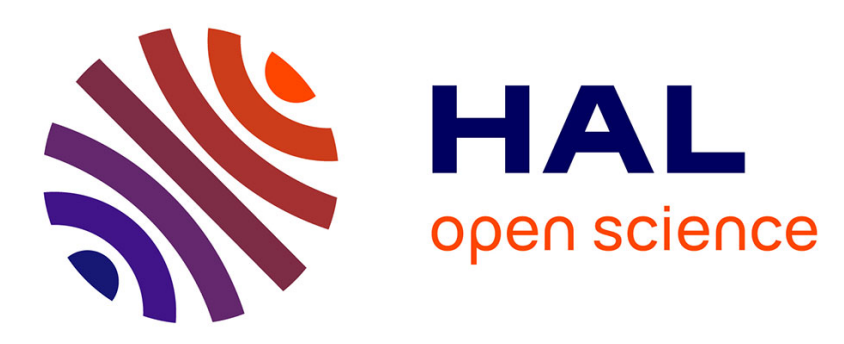

\title{
Streamlined digital bioassays with a 3D printed sample changer
}

\author{
Roberta Menezes, Adèle Dramé-Maigné, Valérie Taly, Yannick Rondelez, \\ Guillaume Gines
}

\section{- To cite this version:}

Roberta Menezes, Adèle Dramé-Maigné, Valérie Taly, Yannick Rondelez, Guillaume Gines. Streamlined digital bioassays with a 3D printed sample changer. Analyst, 2020, 145 (2), pp.572-581. $10.1039 / \mathrm{c} 9 a n 01744 \mathrm{e}$. inserm-02992666

\section{HAL Id: inserm-02992666 https://www.hal.inserm.fr/inserm-02992666}

Submitted on 26 Nov 2020

HAL is a multi-disciplinary open access archive for the deposit and dissemination of scientific research documents, whether they are published or not. The documents may come from teaching and research institutions in France or abroad, or from public or private research centers.
L'archive ouverte pluridisciplinaire $\mathbf{H A L}$, est destinée au dépôt et à la diffusion de documents scientifiques de niveau recherche, publiés ou non, émanant des établissements d'enseignement et de recherche français ou étrangers, des laboratoires publics ou privés. 


\title{
Streamlined digital bioassays with a 3D printed sample changer
}

\author{
Roberta Menezes ${ }^{\mathrm{a}}$, Adèle Dramé-Maignéb, Valérie Talya, Yannick Rondelez ${ }^{\mathrm{b}}$, Guillaume Gines ${ }^{\mathrm{b} *}$
}

\begin{abstract}
a. Centre de Recherche des Cordeliers, INSERM, Sorbonne Université, USPC, Université Paris Descartes, Université Paris Diderot, MEPPOT/ Equipe labellisée Ligue Nationale contre le cancer, F-75006 Paris, France/ INSERM UMR-S1147, CNRS SNC5014.

b. Laboratoire Gulliver, UMR7083 CNRS, ESPCI Paris, PSL Research University, 10 rue Vauquelin 75005 Paris (France).

* Corresponding author

Droplet-based microfluidic has permeated many areas of life sciences including biochemistry, biology and medicine. Water-inoil droplets act as independent femto- to nano-liter reservoirs, enabling the parallelization of (bio)chemical reactions with a minimum sample input. Among the range of applications spanned by droplet microfluidics, digital detection of biomolecules, using Poissonian isolation of single molecules in compartments, has gained considerable attention due to the high accuracy, sensitivity and robustness of these methods. However, while the droplet throughput can be very high, the sample throughput of these methods is poor in comparison to well plate-based assays. This limitation comes from the necessity to convert independently each sample into a monodisperse emulsion. In this paper, we report a versatile device that performs the quick sequential partitioning of up to 15 samples using a single microfluidic chip. A 3D printed sample rotor is loaded with all samples and connected to a pressure source. Simple magnetic actuation is then used to inject the samples in the microfluidic chip without pressure disruption. This procedure generates monodisperse droplets with high sample-to-sample consistency. We also describe a fluorescent barcoding strategy that allows all samples to be collected, incubated, imaged and analyzed simultaneously, thus decreasing significantly the time of the assay. As an example of application, we perform a droplet digital PCR assay for the quantification of a DNA amplicon from 8 samples in less than 2 hours. We further validate our approach demonstrating the parallel quantification of 11 microRNA from a human sample using an isothermal nucleic acid amplification chemistry. As an off-chip device, the sample changer can be connected to a variety of microfluidic geometries and therefore, used for a wide range of applications.
\end{abstract}

\section{Introduction}

Droplet microfluidics has gained considerable attention over the past decade. The use of monodisperse droplets of water-in-oil (w/o) emulsion as independent reactors opens the route to miniaturization, parallelization and saves on reactant costs and sample volume requirements. Emulsionbased assays have spread through many areas of biology, chemistry and beyond. Microfluidic droplets generators are now used to perform chemical reactions ${ }^{1}$, high-throughput screening of experimental conditions $^{2-4}$, protein engineering through directed evolution ${ }^{5-8}$, single cell analysis $^{9-15}$, enzymatic assays ${ }^{16-18}$, digital quantification approaches ${ }^{19-25}$ and colloid fabrication ${ }^{26,27}$, among others. These applications require aqueous droplets with a small size-dispersity, which are usually obtained by forming the droplets at a single oil/water junction (nozzle) under controlled flow conditions. A number of microfluidic designs have been described to produce droplets volume ranging from femtoliter to microliter ${ }^{28-35}$. In addition, approaches to increase the droplet generation rate have been introduced, using for instance multilayer channels ${ }^{36-}$ 39 and parallel microfluidic junctions ${ }^{40-48}$. However, these techniques treat independent samples one by one, with one microfluidic chip required for each new sample. To process multiple samples in a single chip, commercial autosampler systems based on injection loop ${ }^{49,50}$ or pipeting robots ${ }^{51}$, can be coupled to the chip. These systems are relatively expensive. Moreover, the requirement of monodisperse emulsions imposes a precise control of the flows also during sample switching, which may not always be guaranteed. Other custom approaches have also been reported, but they typically target the production of combinatorial component mixtures in larger (nanoliter) droplets $^{4,52}$. For example, Zec et al. designed a custom device made from a capillary combined to a manual XY stage and motorized $\mathrm{z}$-axis to introduce multiple sample slugs in a chip, where they are partitionned into large droplets and further injected with additional compounds ${ }^{53}$. In an attempt to adress the sample throughput issue, Lim et al. recently proposed a microfluidic chip that performs the partitioning of ten samples in parallel using a pressurized chamber ${ }^{55}$. This system, however, is not directly adaptable to different microfluidic devices, as it requires chip redesign and lithography for each specific new application. Moreover, each sample is emulsified in a different microfluidic nozzle, thus microfabrication procedures need to be optimized to avoid sample-to-sample discrepancies ${ }^{55}$. Altogether, in the context of blooming interest for digital bioassays, there is a lack of cheap and versatile approaches to consistently emulsify a large number of independent samples, while minimizing chip consumption. In this article, we present a low-cost, off-chip sample changer that is directly adaptable to any existing microfluidic emulsification devices without modification. Based on a 3D printed sample tray, the sample changer allows for the serial emulsification of up to 15 samples using a single chip, with significantly improved time and reagent usage. This is validated through the simultaneous digital quantification of multiple microRNAs from cell extracts using a recently reported leak-free isothermal amplification chemistry ${ }^{54}$. We discuss potential carry-over contamination issues and shows that they can be efficiently mitigated by introducing 
a.

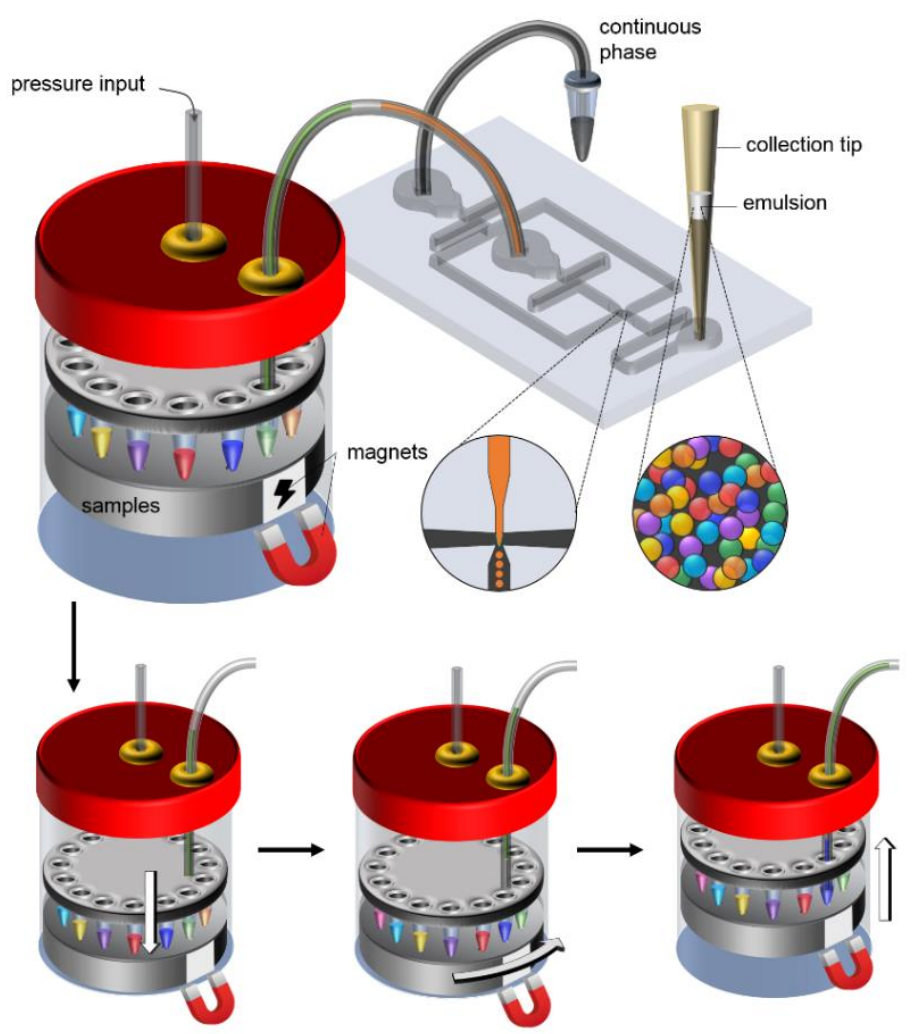

b.

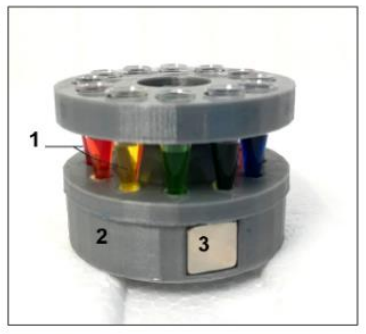
inner magnet outer magnet container reinforcement torus screw cap . PTFE tubing PTFE thread tap 10. microfluidic chip 1. microfluidic chip 11. collection til phase 3. connector to th pressure pump
presto
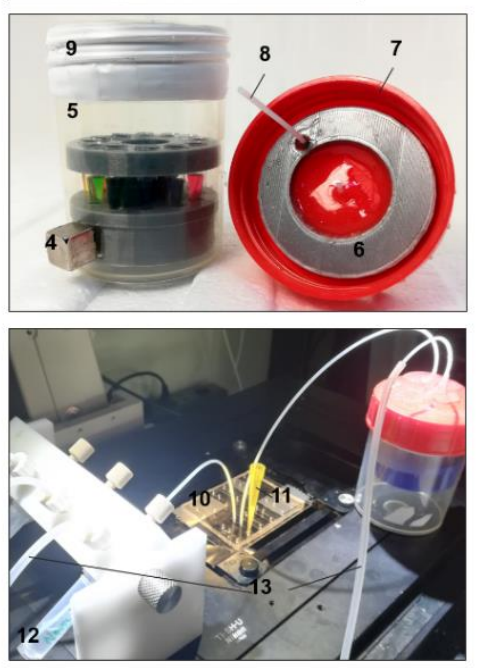

Figure 1. Microfluidic setup. a. The sample changer consists in a 3D printed circular sample tray enclosed in a transparent container. The container is pressurized, allowing the injection of the sample into the microfluidic chip and forming water-in-oil droplets. The samples are sequentially injected in the chip using a magnet to switch the injection tubing from tube to tube. By barcoding the samples with different concentrations of fluorescent molecules (barcodes), all droplets can be collected together, incubated and analyzed at once. b. Annotated pictures of the sample tray (left), with the container (right).

a water plug between each sample. We further demonstrate the possible applications of the off-chip device by performing the quantification of a DNA target from 8 samples by droplet digital PCR in less than 2 hours.

\section{Results and Discussion}

Our approach relies on the serial emulsification of samples in a single chip, using an off-chip 3D printed circular holder which is initially loaded with the different solutions, each in a PCR tube (Figure 1). This holder is inserted in an air-tight container. A tubing is plugged through the top of the container and plunged into the sample mixture contained in the first tube. The other extremity of the tubing is plugged to the water inlet of the microfluidic chip. Using a pressure pump, the container is pressurized, thereby injecting the first sample in the chip. Given that an oil/surfactant mixture is simultaneously injected to the continuous phase inlet, monodisperse droplets are generated at the fluidic junction and collected at the chip outlet. Once the emulsification of the first sample is completed, the sample holder is rotated in order to plunge the tubing into the second sample. This is achieved using a magnetic actuation, without opening the container. The sample holder encases a strong permanent magnet in its design, and a second magnet, placed outside of the container, is used to move the holder on its vertical and rotational axis. This simple procedure permits the quick serial emulsification of all loaded samples using a single chip.

In this approach, all emulsified samples exit the chip through the same outlet. It is therefore necessary to keep track of which droplet originated from which sample. Since most droplet-based digital assays incorporate a fluorescent readout strategy, we reasonned that droplet indexing would be best achieved using a fluorescent barcoding stategy. Each sample, before emulsification, is therefore spiked with a unique combination of fluorescent dyes. All droplets are then collected in a single tube and randomly mixed during manipulation and incubation. At the time of analysis, the barcode fluorescence intensities provide an unambiguous assignment of each droplet to the original sample. This approach has the additional benefit of significantly decreasing the total sample-to-result time and effort because, following serial emulsification, all samples are manipulated in a single tube. For this fluorescent barcoding approach, we used soluble fluorophoreconjugated dextrans, which are known to be inert for the biochemical reactions used here ${ }^{4}$ and do not partitionate into the oil or exchange between droplets during incubation. To evaluate this barcoding approach, we generated $20 \mu \mathrm{m}$ droplets using a flow focusing device (Figure S1). Figure 2 presents the analysis of a mixture of 
a.

\begin{tabular}{|c|c|c|c|}
\hline sample & Alexa647 & Alexa488 & $\begin{array}{c}\text { Cascade } \\
\text { Blue }\end{array}$ \\
\hline \hline 1 & 0 & 0 & 0 \\
2 & 100 & 0 & 0 \\
3 & 0 & 100 & 0 \\
4 & 0 & 0 & 100 \\
5 & 100 & 100 & 0 \\
6 & 100 & 0 & 100 \\
7 & 0 & 100 & 100 \\
8 & 100 & 100 & 100 \\
9 & 200 & 0 & 0 \\
10 & 0 & 200 & 0 \\
11 & 0 & 0 & 200 \\
12 & 200 & 200 & 0 \\
13 & 200 & 200 & 0 \\
14 & 0 & 200 & 200 \\
15 & 200 & 200 & 200 \\
\hline
\end{tabular}

c.

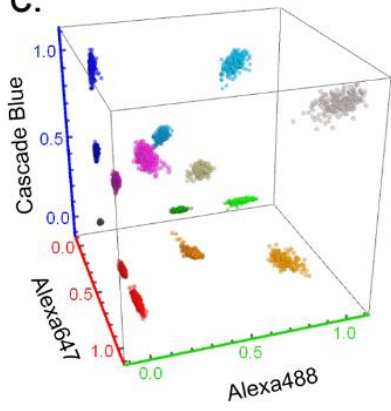

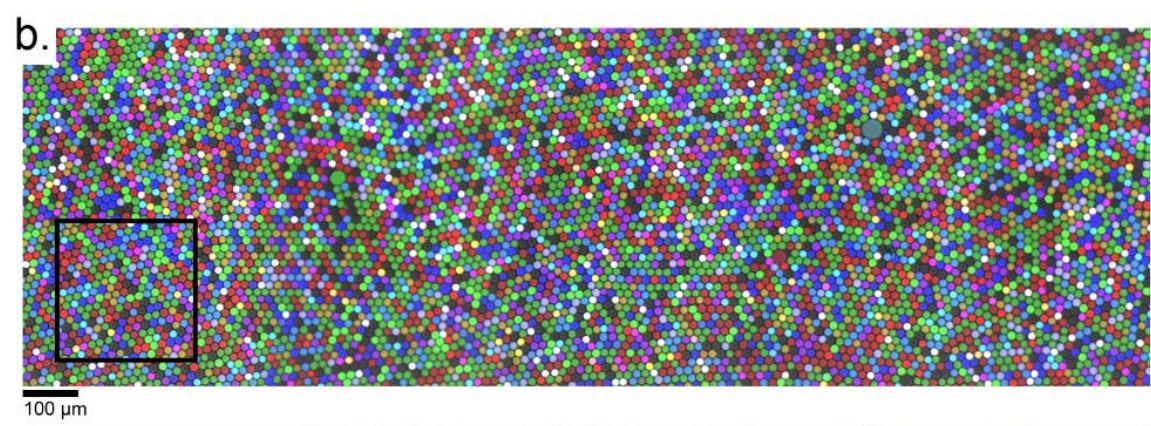

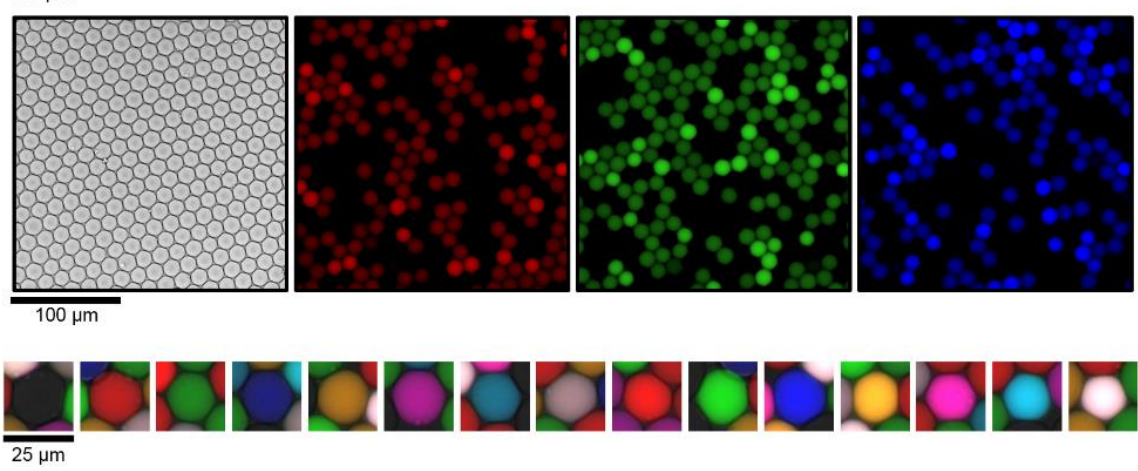

Figure 2. Serial emulsification of 15 samples in $20 \mu \mathrm{m}$ water-in-oil droplets. The samples correspond to water solutions of different barcode combinations (Alexa488, Alexa647 or CascadeBlue-conjugated dextrans at 0, 100 or 200 nM). a. Barcode concentrations of each sample. b. Microscopy snapshots of a droplets array. c. 3D plot of the 15 barcoded droplets populations.

emulsions produced from 15 different samples, barcoded with combinations of three fluorescent dyes (Figure 2a). After emulsification, the mixture of all water-in-oil droplets is collected and sandwiched between two hydrophobic glass slides, before imaging by epifluorescence microscopy. Figure $2 \mathrm{~b}$ presents microscopy snapshots of the droplet array, together with representative images of each of the 15 droplet populations. Figure 2c (see also extended data in Figure S2) shows the precise clustering of each population according to its fluorescent intensity in the three barcode channels. This emulsification/barcoding procedure therefore provides a straighforward way to produce waterin-oil droplets from multiple samples, which are later easily distinguishable via their barcode identity.

Because the sample changer device is independent from the chip, it can be connected to any other microfluidic device, with no need for redesign. At the same time, because all droplets are generated in the same flow-focusing nozzle and without pressure perturbation, we expect sample-tosample droplet discrepancies to be minimal. Figure 3 presents a set of experiments, where barcoded samples were processed through flow focusing microfluidic junction of various widths and geometries. Analysis of the droplet size demonstrates the monodispersity of the emulsions (mean coefficient of variation intra sample of $2.1 \%$ for $9.6 \mu \mathrm{m}$ droplets, $1.7 \%$ for $28 \mu \mathrm{m}$ droplets and $1.9 \%$ for $6.8 \mu \mathrm{m}$ droplets in co-flow geometry) and the conservation of the size throughout the generation (coefficient of variation of the mean diameter across samples $<3 \%)$.
Droplet digital assays have emerged as attractive analytical methods that enable the absolute quantification of nucleic acids, cells or proteins. However, while microplate-based tests are routinely conducted on dozens to hundreds of measurement in parallel, it is not trivial to obtain a similar sample throughput for digital formats. This limitation comes from the necessity to partition independently each sample into thousands to millions of compartments; microdroplet technologies are notoriously difficult to parallelize on multiple samples. Commercial platforms are available for standard assays such as digital $\mathrm{PCR}^{56,57}$ or digital immuno assay ${ }^{58}$. However, these expensive instruments can process only a few samples and/or require high-tech autosampler.

To demonstrate the usefulness of our 3D printed device on practical applications, we performed the digital detection of 11 microRNA targets from a human colon extract, using a previously reported isothermal and digital quantification method (Figure 4a) ${ }^{54}$. Briefly, 4 oligonucleotides (a converter template, an amplification template, a pseudotemplate and a reporting template) and 5 enzymes (a DNA polymerase Vent(exo-), two nicking enzymes Nt.BstNBI and Nb.BsmI, an exonuclease ttRecJ and a restriction enzyme BsmI) are required to exponentially amplify a fluorescent signal from single microRNAs isolated in microdroplets. If present, the microRNA is converted to a short oligonucleotide (12 bases trigger) by the microRNA-specific converter template, using extension-nicking reactions. 
a.
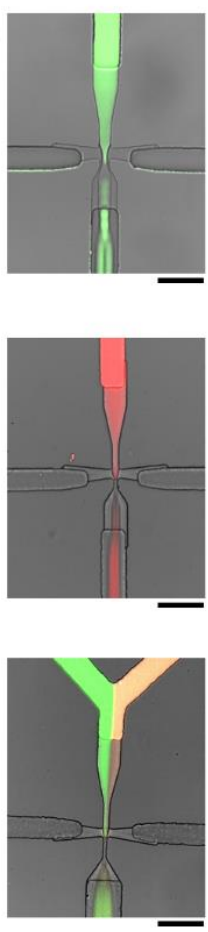

b.
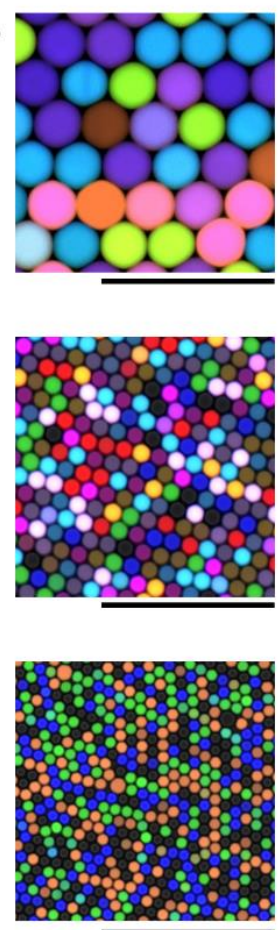
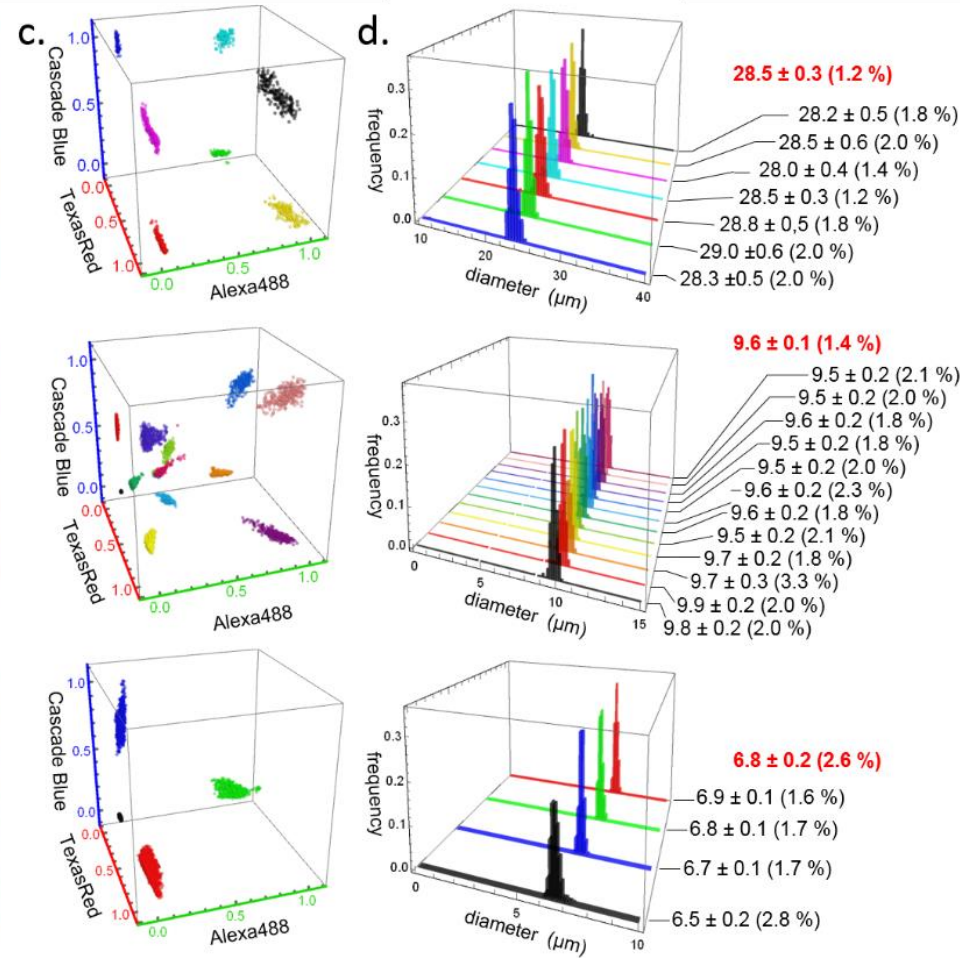

Figure 3. Off-chip sample changer adaptable to various microfluidic devices. a. Three flow focusing junctions were tested: emulsification of 7 samples (labeled with TexasRed, Alexa488 and CascadeBlue-conjugated dextrans) using a $20 \mu \mathrm{m}$ wide nozzle (top), emulsification of 12 samples using a $10 \mu \mathrm{m}$ wide nozzle (middle) and emulsification of 4 samples using a $7 \mu \mathrm{m}$ wide nozzle, co-flow geometry. For the latter device, the sample changer is connected to the left inlet (green fluorescence) while the right inlet is connected to a buffer solution. b. Snapshots of the imaging chambers. c. 3D plot of the barcoded droplets populations. d. Size distribution for each droplet population (> 500 droplets counted for each population, cf. Material and Method for the estimation of the droplet size). Numbers in brackets are the coefficents of variation. The top red numbers represent the size dispersion over all droplets populations. Scale bars $=100 \mu \mathrm{m}$.

The trigger is then exponentially amplified on the amplification template. The pseudotemplate ensures that nonspecific amplification does not occur in the absence of the targeted microRNA ${ }^{59}$. Finally the profluorescent reporting template captures the trigger strand, leading to an increased fluorescence emission. By designing the converter template complementary to the sequence of interest, this amplification method can be repurposed to detect, in principle, any microRNA. For example, the quantification of the microRNA Let7a in total RNA extract from human colon is presented in Figure S3. We observe a linear correlation between the measured concentration of Let7 $\mathrm{a}$ and the total RNA concentration that validates the reliability of the quantification. From a previous study, a limit of detection as low as 1-10 fM has been reported ${ }^{54}$.

However, using such strategy, a multiplex assay would involve the generation of emulsions from sample mixtures containing each a different converter template targeting one of the desired microRNA. In the experiment presented in Figure 4b-d, 12 samples were prepared corresponding to 10 amplification mixtures with different converter templates targeting human microRNA, plus 1 positive control containing a converter template targeting a nonhuman microRNA (cel-mir39) and 1 negative control without converter template. The 12 samples, spiked with 2 $\mathrm{ng} / \mu \mathrm{L}$ of total RNA extracted from human colon cells and $1 \mathrm{pM}$ of synthetic cel-mir39, were sequentially emulsified and collected in the same tube. The emulsion was then incubated at $50^{\circ} \mathrm{C}$ for 4 hours and the droplets were imaged by fluorescent microscopy (Figure $4 \mathrm{~b}$, details on the analysis are provided in Figure S4). For each population, indentified from their barcode intensity, the ratio of positive versus negative droplets (Figure 4c) was calculated allowing for the absolute quantification of each of the 11 microRNAs using Poisson statistics (Figure 4d). In the sample with no converter template, 1 false positive event was detected, while $1.01 \mathrm{pM}$ (expected $1 \mathrm{pM}$ ) of cel-mir39 were quantified in the positive control. The real-time monitoring of the bulk reaction mixtures was performed in parallel to the digital assay (Figure S4a-b), showing, as expected, a correlation between the measured concentration from the digital readout and the amplification time provided by analog measurement. Altogether, these results demonstrates the accuracy of the quantification method. A significant amount of human microRNA was successfully detected for all targets, ranging from $\sim 90 \mathrm{fM}($ mir224) to $\sim 600 \mathrm{fM}$ (Let7a). This microfluidic platform thus provides a straigthforward method for microRNA profiling that could find applications in the identification of disease-related biomarker signatures. 
a.

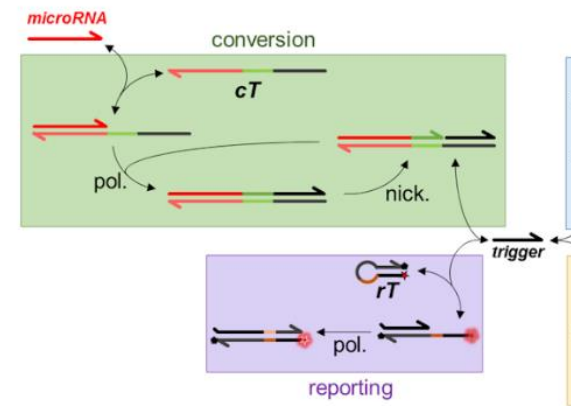

amplification

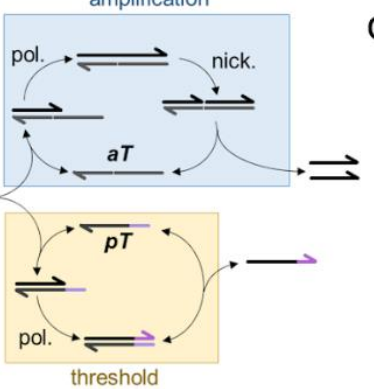

d.

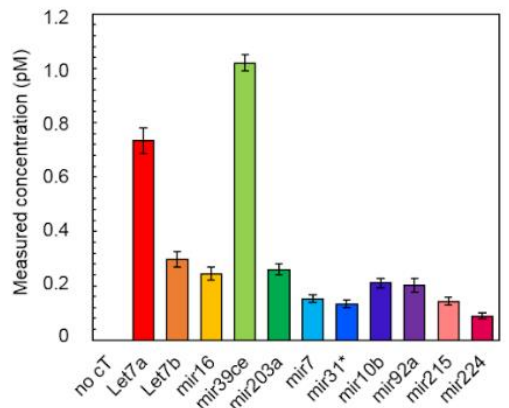

b.
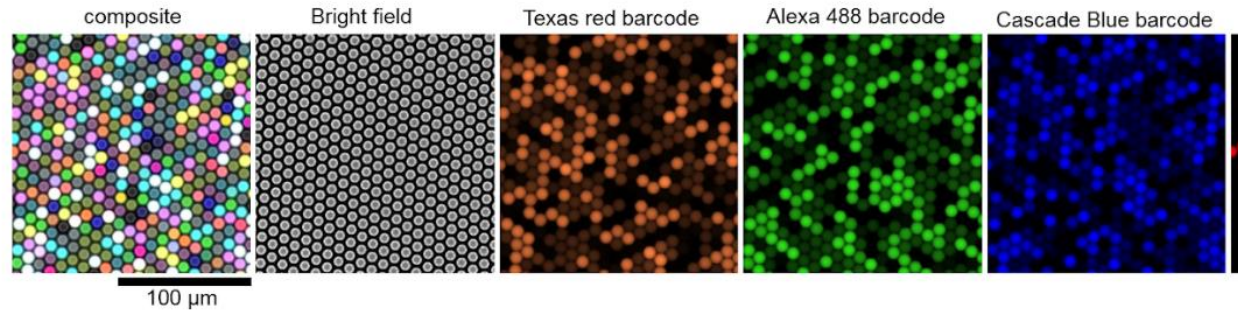

Atto633 rT

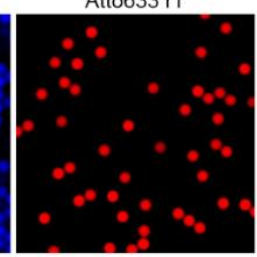

C.

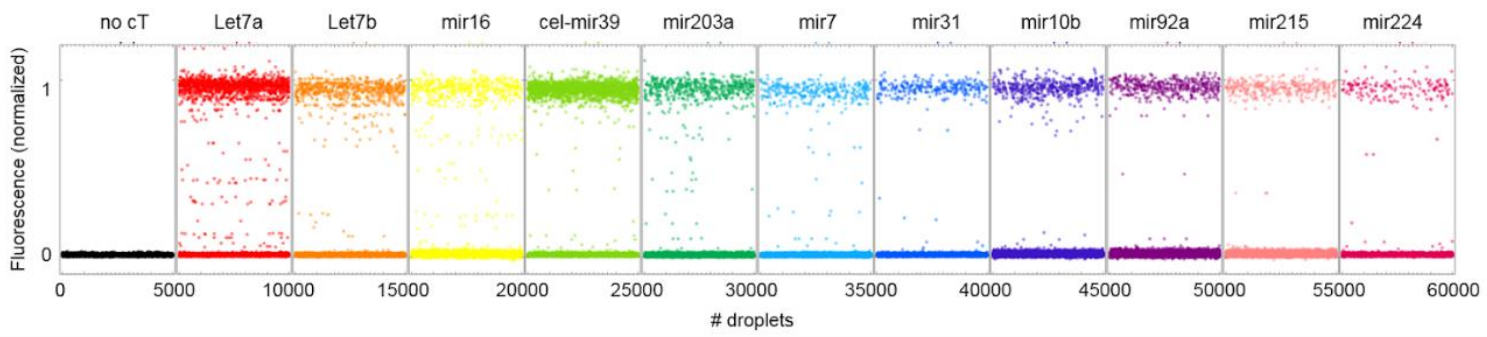

Figure 4. Parallelized detection of microRNA from human total RNA extract. a. Isothermal amplification strategy used for the study, based on a previously reported background-free molecular amplifier. It relies on the signal amplification of a 12 base DNA trigger using polymerization/nicking mechanism on an autocatalytic template (aT). A pseudotemplate ( $\mathrm{pT}$ ) is added to the system to absorb the leak coming from spurious reactions on the autocatalytic template, avoiding background amplification. The target specificity is guaranteed by a converter template (cT) that, upon hybridization of the microRNA target, produces the trigger sequence. The amplification is visualized with a dual-labelled reporting template ( $\mathrm{rT}$, labelled with Atto633 fluorophore and BHQ2 quencher) that emits fluorescence when bound to the trigger sequence. b. Microscopy images of the 12 droplet populations (CascadeBlue, TexasRed, Alexa488-tagged dextrans) after amplification. c. Normalized fluorescence for each droplet population. d. Measured concentration, computed from Poisson statistics. Error bars based on $95 \%$ confidence interval.

As the droplets are generated sequentially, through the injection of different samples in the same tubing and microfluidic chip, this raised the question of carry-over contamination. Note that carry-over may be a concern when attempting to quantify sequentially the same target from different samples, and not when measuring different targets from a single sample (as in Figure 4). Sample-tosample carry-over has been studied by others, in particular regarding the issue of cross contamination in continuous PCR assay ${ }^{60-64}$. Curcio and Roeraade demonstrated that the introduction of a water slug in between two samples reduces considerably the carry-over contamination over droplets traveling in teflon tubing ${ }^{64}$. To investigate this question in our experimental setup, we performed the alternate emulsification of two samples, one being a negative control ( 0 pM target) and the other a positive control (1 pM target Let7a) (Figure 5). Between each sample, a volume of $2 \mu \mathrm{L}$ of ultrapure water is injected from the sample changer in order to rinse the tubing and the device. From the triplicate samples NC2, NC3 and NC4, we estimated the carry-over contamination to be arround $0.7 \%$. Although not negligible, this residual carry-over contamination can be considered low enough to allow a proper quantification of the positive samples used here.

Another potential application of our serializing approch is the calibration and validation of digital assays using standard samples. To demonstrate this using a different chemistry, we performed a droplet digital PCR (ddPCR) ${ }^{65,66}$

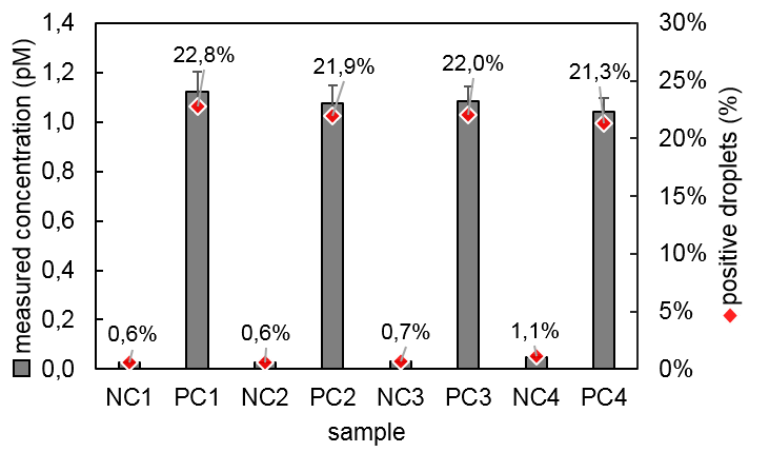

Figure 5. Carry-over contamination across samples. Negative controls (NC, no target) and positive controls (PC, 1 pM Let7a) are alternatively emulsify using the sample changer. The graph report the percentage of positive droplets and corresponding concentrations for each sample. 
a.

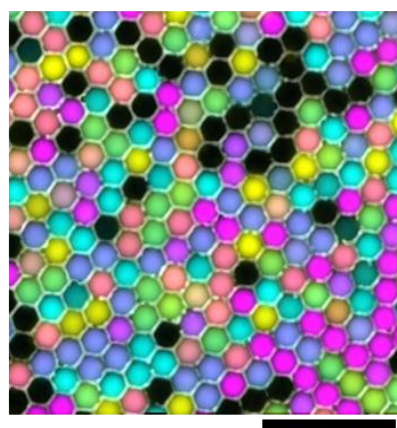

$50 \mu \mathrm{m}$

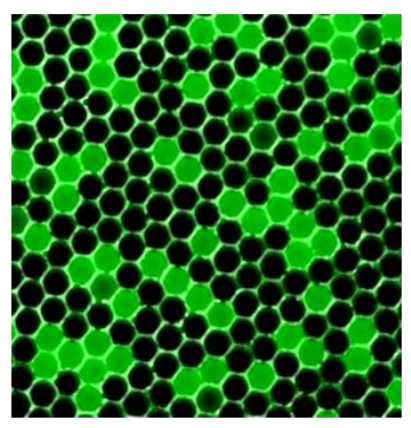

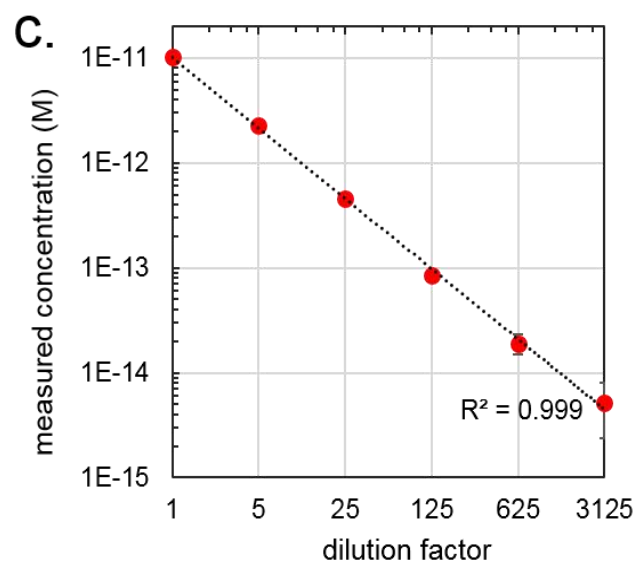

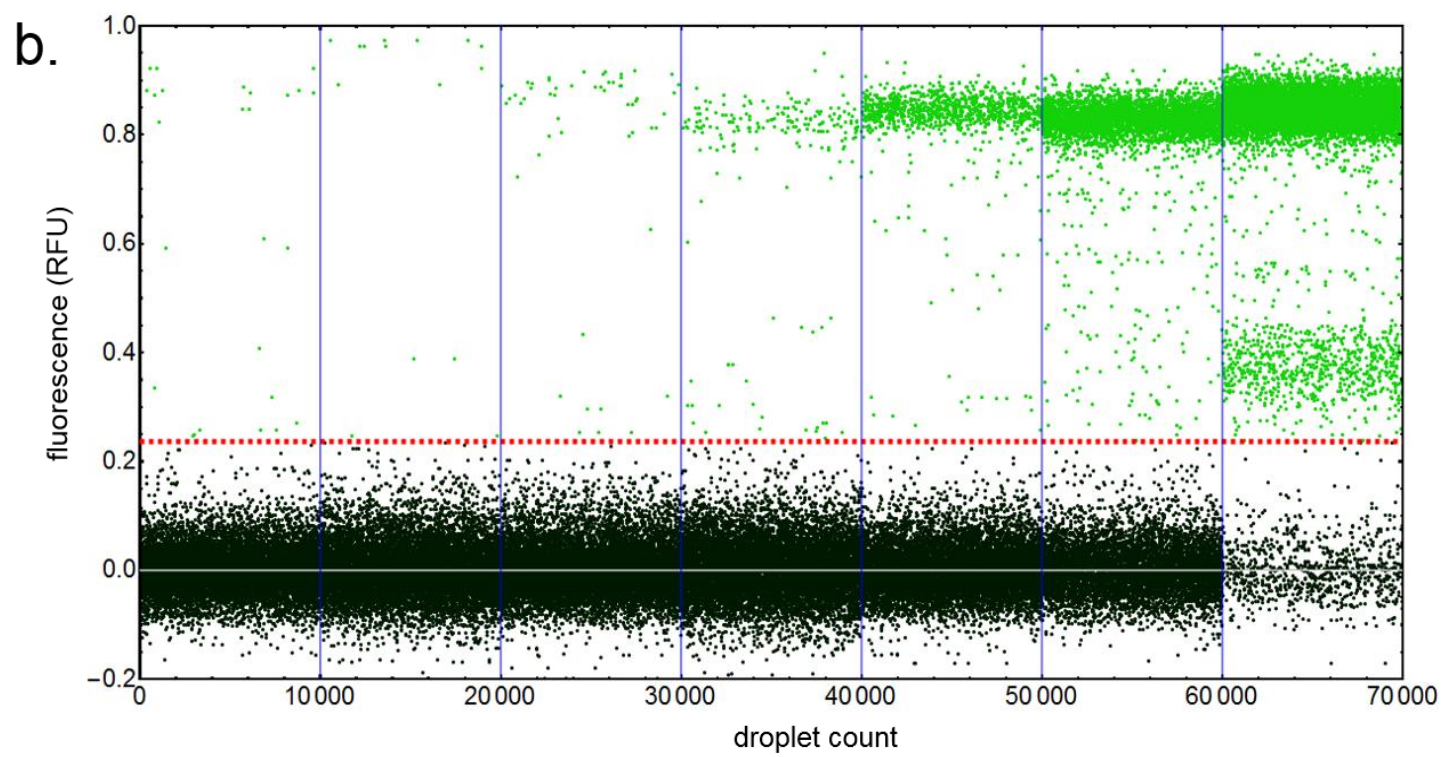

Figure 6. Droplet digital PCR of a 163 base amplicon from the Nt.bstNBI gene incorporated in the plasmid psB3K3. Barcoded samples (CascadeBlue, TexasRed, Alexa647) corresponding to a serial dilution of the target sequence are distributed in water-in-oil droplets and the targets are amplified by PCR. a. Microscopy snapshots of a portion of the imaging chamber: The droplet population are segmented using the barcode fluorescence (left, composite image) and the amplification is visualized using the double strand-specific dye EvaGreen (right). b. Positive event detected for each droplet population. c. The measured concentration computed from the Poisson law is plotted as a function of the dilution factor. Error bars correspond to the $95 \%$ confidence interval. The data points are fitted with a linear regression.

of a 163-mer amplicon from the template plasmid psB3K3 containing the Nt.bstNBI gene fused with the gfp gene. PCR mixes spiked with a serially diluted DNA template are serially emulsified and the droplets are thermocycled and analysed by fluorescence microscopy. The result of the ddPCR is reported in Figure 6. In accordance with the experiment design, we observe a linear correlation $\left(\mathrm{R}^{2}=\right.$ $0.99)$ between the measured template concentration and the dilution factor. The assay time is below 2 hours (20 minutes for sample preparation, 30 minutes of droplet generation, 30 minutes of PCR amplification and 30 minutes for data analysis), which allows multiple ddPCR to be performed routinely without specific digital PCR instrumentation. This approach is for example suitable for precise DNA quantification (plasmids or other expression vectors, genomic DNA, qPCR standard or NGS libraries), classically performed using absorbance or fluorescence measurements, which may be prone to inaccuracy.

\section{Conclusion}

We have presented a low cost sample changer device made from a 3D printed magnetic holder inserted in a pressurized compartment. This off-chip device can be adapted to any microfluidic device to increase the sample throughput. In most droplet-based protocols, only a small fraction of droplets are analyzed (tens to hundreds of thousands) but much more are generated to facilitate the manipulation of the emulsions. In our approach, emulsions coming from many samples are collected in the same vial, processed and analyzed simultaneously, dramatically reducing the time and effort required. Since the internal pressure is not perturbed, all samples are emulsified in an homogenous and consistent manner. As an example, the quantification of a target microRNA from 15 samples individually would require the emulsification of $10 \mu \mathrm{L}$ per sample. Considering a generation rate of $10 \mathrm{kHz}$ and a droplet volume of $0.5 \mathrm{pL}$, 
it would take 30 minutes per sample, hence more than 7 hours of generation. Using our sample changer, less than 1 $\mu \mathrm{L}$ of each sample is injected into the chip and the emulsions are collected together resulting in a final volume of $\sim 15 \mu \mathrm{L}$, enough to be easily manipulated, while cutting down the generation time to less than 1 hour. Using a very sensitive digital assay, we also show that a water slug introduced between each sample is enough to wash possible contaminants and avoid sample-to-sample contamination. Easy to fabricate and user-friendly, the sample changer possesses two main advantages: i) the cost ( $\sim 3$ euros for a 15-sample device, including the printing filament, the two magnets and the container, cf. the Material and Methods section), which is orders of magnitude lower than commercially available platforms ${ }^{49-}$ 51; and ii) the versatility, as it can be connected to a wide range of pre-existing microfluidic devices and therefore find broad applicability. However, some improvements could still boost its capacities. For example, we used here a sample rack with 15 positions loaded in a container of 52 $\mathrm{mm}$ in diameter. Using a larger container, it should be possible to scale up the number of samples. Another limitation of our approach is that switching from one sample to the other is a manual process, involving the manipulation of the sample changer by the user using a magnet. Future developments will aim at automatizing the sample changer using a programmable motorized rotor acting as a versatile autosampler.

\section{Material and Methods}

\section{Sample changer fabrication}

The sample tray was designed in OpenSCAD and 3D printed using an Ultramaker III printer loaded with PLA filament. After assembling, a cubic $1 \mathrm{~cm}$ neodymium magnet is inserted in the tray. The details of the design are provided in Figure S5. A cylindrical container $(52 \mathrm{~mm}$ diameter, Corning Gosselin) made of clear propylene is used to fit the sample rack. The screw cap is drilled with two holes through which the two segments of tubing are introduced: a central tubing providing input pressure and an side tubing from in the sample tubes to the device. To ensure the proper air-tightness of the pressurized container, the tubings are glued to the cap with an epoxy resist and a layer of PTFE ribbon is coiled around the screw thread.

\section{Microfluidic devices}

Masks were designed using AutoCAD and phototraced on transparent film (Selba S.A., Switzerland). Molds were fabricated using standard multilayer soft lithography techniques. Briefly, microfluidic channels were patterned on 4-inch silicon wafers spin coated with $5 \mathrm{~mL}$ of SU-8 photoresist (MicroChem Corp., MA, USA), baked, exposed to UV and developed. After cleaning with isopropanol and dried, molds were covered by a $5 \mathrm{~mm}$ layer of polydimethylsiloxane (PDMS, Dow Corning, Sylgard 184) mixed with the curing agent in a ratio $10: 1 \mathrm{w} / \mathrm{w}$ and baked for 2 hours at $70{ }^{\circ} \mathrm{C}$. After pilling of the PDMS slab, inlets and outlets were drilled with a biopsy puncher of $1.5 \mathrm{~mm}$ diameter (Integra Miltex, PA, USA) . The PDMS chip are bound onto a $1 \mathrm{~mm}$ thick glass slide (Paul Marienfeld, GmbH \& Co. K.G., Germany) sequentially cleaned with acetone and isopropanol, immediately after oxygen plasma exposure. The chips are finally baked at $200^{\circ} \mathrm{C}$ for 5 hours to make the channels hydrophobic ${ }^{67}$.

\section{Droplet generation}

To monitor the generation in real-time, the microfluidic chip was positionned on a brightfield microscope. The sample changer and the continuous phase were connected to the microfluidic inlets using PTFE tubing 1/16"x0.2 mm inner diameter (Cluzeau Info Labo, France). The continuous phase is composed of fluorinated oil (Novec$7500,3 \mathrm{M})$ containing $1 \%$ or $4 \%(\mathrm{w} / \mathrm{w})$ fluorosurfactant (Fluosurf, Emulseo, France) for isothermal amplification and PCR amplification, respectively. Samples were spiked with concentrations comprised between 0 and $200 \mathrm{nM}$ of dextran-conjugated dye including Dextran Texas Red 70,000 MW, Dextran Alexa Fluor 488 3,000 MW, Dextran Alexa Fluor 647 10,000 MW, Dextran Cascade Blue 10,000 MW Lysine fixable (ThermoFisher Scientific). Droplets were generated by hydrodynamic flow focusing using a pressure pump controller (MFCS-EZ, Fluigent, France). Samples were emulsified serially by switching the tubing position using the external magnet to manipulate the sample rack. An air bubble and optionally a water slug (0.5 $\mu \mathrm{L} \sim 1.5 \mathrm{~cm}$ of PTFE tubing) were inserted between each sample. The droplets were collected at the outlet using a $200 \mu \mathrm{L}$ pipet tip (LoRetention tip, eppendorf).

\section{Droplet imaging}

Droplets were analyzed by transmission and epifluorescent microscopy. A 70x50x1 mm glass slide (Paul Marienfeld, GmbH \& Co. K.G., Germany) was made hydrophobic by pouring $3 \mathrm{~mL}$ Novec $1720(3 \mathrm{M})$ and baked for 1 minute at $100{ }^{\circ} \mathrm{C}$ on a heating plate. Polystyrene beads (Polysciences, Inc., PA, USA) slightly larger than the droplets, used as hard spheres spacers, were spotted on the glass slide and left for evaporation at $100^{\circ} \mathrm{C}$. The emulsion was deposited on the glass slide and covered with a $22 \times 22 \mathrm{~mm}$ coverslip (VWR) treated with Novec 1720. For Figures 4, 5 and 6 a minimum of $5,000,5,000$ and 10,000 droplets were analyzed respectively. The coverslip was gently pressed to obtain a monolayer array of close-packed droplets. The chamber was sealed with an epoxy glue (Sader) and images were acquired using an epifluorescence microscope Nikon Eclipse Ti equipped with a motorized XY stage (Nikon), a camera Nikon DS-Qi2 and a CoolLed pE-4000 illumination source. Depending on the droplet size, apochromatic 10X (N.A. 0.45, WD 4.0) or 20X (N.A. 0.75, WD 1.0) objectives were used. False-color images were generated with the open source ImageJ software. 


\section{Data analysis}

Quantitative data were extracted using Mathematica software (Wolfram). Briefly, droplets were segmented using the bright field image. The droplet diameter was estimated assuming a spherical shape (as polystyrene beads larger that the droplets are used as spacer between the bottom and top slides). The components were filtered according to their size (to eliminate the bigger droplets resulting from coalescence or instability during the generation) and circularity (to eliminate non-circular components). After extracting the centroids, the fluorescence of each droplet from each channel was averaged. The optical crosstalk between red and orange channels was compensated and the droplet populations were then sorted according to the barcodes' intensity. The output measurement (microRNA concentration, DNA fragment concentration, $95 \%$ confidence interval) was then computed for each sample, as described elsewhere ${ }^{68}$. More details are provided in Figure S6.

\section{Detection of microRNA using isothermal amplification.}

HPLC-purified oligonucleotides were obtained from Biomers (Germany) and stored at $-20{ }^{\circ} \mathrm{C}$. Human colon total RNA extracts were purchased from (Thermofisher Scientific, aliquoted at $1 \mathrm{mg} / \mathrm{mL}$ and stored at $-80{ }^{\circ} \mathrm{C}$. Sequences, available from the 
Table S 1, were designed according to previously reported rules ${ }^{59,69}$. All reaction mixtures were assembled at $4{ }^{\circ} \mathrm{C}$ in $200 \mu \mathrm{L}$ PCR tubes. The four templates (autocatalytic template, pseudotemplate, conversion template, reporting template, at a final concentration of $50,12,0.5,40 \mathrm{nM}$ respectively) were mixed with the reaction buffer $(20 \mathrm{mM}$ Tris $\mathrm{HCl} \mathrm{pH} \mathrm{7.9,} 10 \mathrm{mM}\left(\mathrm{NH}_{4}\right)_{2} \mathrm{SO}_{4}, 40 \mathrm{mM} \mathrm{KCl}, 10 \mathrm{mM}$ $\mathrm{Mg}_{2} \mathrm{SO}_{4}, 50 \mu \mathrm{M}$ each dNTP, $0.1 \%$ (w/v) Synperonic F $10^{4}$, $2 \mu \mathrm{M}$ netropsin, all purchased from Sigma Aldrich). The enzyme mixture (BSA $200 \mu \mathrm{g} / \mathrm{mL}, \mathrm{NbBsmI} 200 \mathrm{u} / \mathrm{mL}$, Vent(exo-) DNA polymerase $80 \mathrm{u} / \mathrm{mL}$, Nt.BstNBI 80 $\mathrm{u} / \mathrm{mL}, \mathrm{BsmI} 70 \mathrm{u} / \mathrm{mL}$ (all from New England Biolabs) home-purified ttRecJ exonuclease ${ }^{70} 23 \mathrm{nM}$ ). After droplet generation, the emulsion was incubated at $50^{\circ} \mathrm{C}$ in a qPCR thermocycler (CFX96 Touch, Bio-Rad) for 3 hours. The droplets were finally analyzed as described above.

\section{Droplet digital PCR}

All PCR reaction mixtures were assembled at $4^{\circ} \mathrm{C}$ in 200 $\mu \mathrm{L}$ PCR tubes. PCR reactions consisted in $1 \mathrm{X}$ Thermopol Buffer (New England Biolabs, $20 \mathrm{mM}$ Tris- $\mathrm{HCl}$ pH 8.8, 10 $\mathrm{mM}\left(\mathrm{NH}_{4}\right)_{2} \mathrm{SO}_{4}, 10 \mathrm{mM} \mathrm{KCl}, 2 \mathrm{mM} \mathrm{MgSO}_{4}, 0.1 \%$ Triton X-100) supplemented with $200 \mu \mathrm{M}$ each dNTP, $200 \mathrm{nM}$ forward (CCATGCTAAGGAATTACAG) and reverse (ATTTTTATTTGGAATGAAGCG) primers, $0.5 \mathrm{X}$ Evagreen (Biotium, Inc., CA, USA), $0.4 \% \mathrm{w} / \mathrm{v}$ Pluronic F127 (Merk), $200 \mu \mathrm{g} / \mathrm{mL}$ BSA and $40 \mathrm{u} / \mathrm{mL} \operatorname{Vent}($ exo-) DNA polymerase. Various dilution of a $5.5 \mathrm{~kb}$ plasmid psB3K3 containing the Nt.bst NBI gene fused in c-terminal with the $g / P$ gene were used as template for the reaction. qPCR or ddPCR amplification were performed in CFX one touch instrument (Biorad): samples were first heated at 95 ${ }^{\circ} \mathrm{C}$ for 5 minutes followed by 20 cycle (ddPCR) or 40 cycles (qPCR) of $95^{\circ} \mathrm{C}$ for $30 \mathrm{~s}, 53^{\circ} \mathrm{C}$ for $30 \mathrm{~s}, 72{ }^{\circ} \mathrm{C}$ for $20 \mathrm{~s}$. Optionally, a melt curve was recorded at the end of the run by heating the sample from 20 to $95^{\circ} \mathrm{C}$ and measurement the fluorescence each $0.5^{\circ} \mathrm{C}$. PCR products were analyzed by gel electrophoresis using $0.8 \% \mathrm{w} / \mathrm{v}$ agarose gel (Figure S7). Droplet imaging was performed as described above using a 20X magnitification objective. Interestingly, we noticed that Evagreen photobleached faster in positive droplets than in target-free droplets, which results in an increased signal-to-noise ratio (Figure S8). Each frame was thus exposed for 20 seconds at $100 \%$ illumination power, prior to image acquisition.

\section{Conflicts of interest}

There are no conflicts to declare

\section{Acknowledgements}

This research was supported by PSL Research University and the ERC Grant "DeepMiR". This work was supported by the Universite Paris-Descartes, the Centre National de la Recherche Scientifique (CNRS), the Institut National de la Santé et de la Recherche Médicale (INSERM), the ligue nationale contre le cancer (LNCC, Program "Equipe labelisée LIGUE”; no. EL2016.LNCC/VaT). R.M. received a fellowship from ITMO cancer within the Frontiers in Life Science PhD program (FdV).

\section{References}

1 H. Song, D. L. Chen and R. F. Ismagilov, Angewandte Chemie International Edition, 2018, 7336-7356.

2 J. Ferreira, F. Castro, F. Rocha and S. Kuhn, Chemical Engineering Science, 2018, 191, 232-244.

3 B. Zheng, L. S. Roach and R. F. Ismagilov, J. Am. Chem. Soc., 2003, 125, 11170-11171.

4 A. J. Genot, A. Baccouche, R. Sieskind, N. AubertKato, N. Bredeche, J. F. Bartolo, V. Taly, T. Fujii and Y. Rondelez, Nature Chemistry, 2016, 8, 760-767.

5 D. S. Tawfik and A. D. Griffiths, Nature Biotechnology, 1998, 16, 652.

6 A. D. Griffiths and D. S. Tawfik, Trends in Biotechnology, 2006, 24, 395-402.

7 R. Obexer, A. Godina, X. Garrabou, P. R. E. Mittl, D. Baker, A. D. Griffiths and D. Hilvert, Nature Chemistry, 2017, 9, 50-56.

8 B. Kintses, C. Hein, M. F. Mohamed, M. Fischlechner, F. Courtois, C. Lainé and F. Hollfelder, Chemistry \& Biology, 2012, 19, 1001-1009.

9 E. Brouzes, M. Medkova, N. Savenelli, D. Marran, M. Twardowski, J. B. Hutchison, J. M. Rothberg, D. R. Link, N. Perrimon and M. L. Samuels, $P N A S, 2009$, 106, 14195-14200.

10 J. F. Edd, D. D. Carlo, K. J. Humphry, S. Köster, D. Irimia, D. A. Weitz and M. Toner, Lab Chip, 2008, 8, 1262-1264.

11 P. Dalerba, T. Kalisky, D. Sahoo, P. S. Rajendran, M. E. Rothenberg, A. A. Leyrat, S. Sim, J. Okamoto, D. M. Johnston, D. Qian, M. Zabala, J. Bueno, N. F. Neff, J. Wang, A. A. Shelton, B. Visser, S. Hisamori, Y. Shimono, M. van de Wetering, H. Clevers, M. F. Clarke and S. R. Quake, Nature Biotechnology, 2011, 29, 1120-1127.

12 H. C. Fan, J. Wang, A. Potanina and S. R. Quake, Nature Biotechnology, 2011, 29, 51-57.

13 F. Lan, B. Demaree, N. Ahmed and A. R. Abate, Nature Biotechnology, 2017, 35, 640-646.

14 L. Liu, C. K. Dalal, B. M. Heineike and A. R. Abate, Lab Chip, 2019, 19, 1838-1849.

15 Y. Zhang and H. Noji, Anal. Chem., 2017, 89, 92-101.

16 C. Chang, J. Sustarich, R. Bharadwaj, A. Chandrasekaran, P. D. Adams and A. K. Singh, Lab Chip, 2013, 13, 1817-1822.

17 N. Wu, F. Courtois, R. Surjadi, J. Oakeshott, T. S. Peat, C. J. Easton, C. Abell and Y. Zhu, Engineering in Life Sciences, 2011, 11, 157-164.

18 T. Beneyton, S. Thomas, A. D. Griffiths, J.-M. Nicaud, A. Drevelle and T. Rossignol, Microb Cell Fact, , DOI:10.1186/s12934-017-0629-5.

19 H. Tanaka, S. Yamamoto, A. Nakamura, Y. Nakashoji, N. Okura, N. Nakamoto, K. Tsukagoshi and M. Hashimoto, Anal. Chem., 2015, 87, 4134 4143. 
20 H. Tian, Y. Sun, C. Liu, X. Duan, W. Tang and Z. Li, Anal. Chem., 2016, 88, 11384-11389.

21 F. Schuler, F. Schwemmer, M. Trotter, S. Wadle, R. Zengerle, F. von Stetten and N. Paust, Lab Chip, 2015, 15, 2759-2766.

22 B. J. Hindson, K. D. Ness, D. A. Masquelier, P. Belgrader, N. J. Heredia, A. J. Makarewicz, I. J. Bright, M. Y. Lucero, A. L. Hiddessen, T. C. Legler, T. K. Kitano, M. R. Hodel, J. F. Petersen, P. W. Wyatt, E. R. Steenblock, P. H. Shah, L. J. Bousse, C. B. Troup, J. C. Mellen, D. K. Wittmann, N. G. Erndt, T. H. Cauley, R. T. Koehler, A. P. So, S. Dube, K. A. Rose, L. Montesclaros, S. Wang, D. P. Stumbo, S. P. Hodges, S. Romine, F. P. Milanovich, H. E. White, J. F. Regan, G. A. Karlin-Neumann, C. M. Hindson, S. Saxonov and B. W. Colston, Anal. Chem., 2011, 83, 8604-8610.

23 V. Taly, D. Pekin, L. Benhaim, S. K. Kotsopoulos, D. L. Corre, X. Li, I. Atochin, D. R. Link, A. D. Griffiths, K. Pallier, H. Blons, O. Bouché, B. Landi, J. B. Hutchison and P. Laurent-Puig, Clinical Chemistry, 2013, 59, 1722-1731.

24 L. Mazutis, A. F. Araghi, O. J. Miller, J.-C. Baret, L. Frenz, A. Janoshazi, V. Taly, B. J. Miller, J. B. Hutchison, D. Link, A. D. Griffiths and M. Ryckelynck, Anal. Chem., 2009, 81, 4813-4821.

25 J. Shim, R. T. Ranasinghe, C. A. Smith, S. M. Ibrahim, F. Hollfelder, W. T. S. Huck, D. Klenerman and C. Abell, ACS Nano, 2013, 7, 5955-5964.

26 E. M. Chan, A. P. Alivisatos and R. A. Mathies, J. Am. Chem. Soc., 2005, 127, 13854-13861.

27 F. Malloggi, N. Pannacci, R. Attia, F. Monti, P. Mary, H. Willaime, P. Tabeling, B. Cabane and P. Poncet, Langmuir, 2010, 26, 2369-2373.

28 P. B. Umbanhowar, V. Prasad and D. A. Weitz, Langmuir, 2000, 16, 347-351.

29 M. Leman, F. Abouakil, A. D. Griffiths and P. Tabeling, Lab Chip, 2015, 15, 753-765.

30 S. L. Anna, N. Bontoux and H. A. Stone, Appl. Phys. Lett., 2003, 82, 364-366.

31 T. Kawakatsu, Y. Kikuchi and M. Nakajima, Journal of the American Oil Chemists' Society, 1997, 74, 317-321.

32 T. Thorsen, R. W. Roberts, F. H. Arnold and S. R. Quake, Phys. Rev. Lett., 2001, 86, 4163-4166.

33 P. Garstecki, M. J. Fuerstman, H. A. Stone and G. M. Whitesides, Lab Chip, 2006, 6, 437-446.

34 T. Nisisako, T. Torii and T. Higuchi, Lab Chip, 2002, 2, 24-26.

35 C. Priest, S. Herminghaus and R. Seemann, Appl. Phys. Lett., 2006, 88, 024106.

36 D. Conchouso, D. Castro, S. A. Khan and I. G. Foulds, Lab Chip, 2014, 14, 3011-3020.

37 T. Nisisako, T. Ando and T. Hatsuzawa, Lab Chip, 2012, 12, 3426-3435.

38 D. R. Link, S. L. Anna, D. A. Weitz and H. A. Stone, Phys. Rev. Lett., 2004, 92, 054503.

39 S. Haeberle, R. Zengerle and J. Ducrée, Microfluid Nanofluid, 2007, 3, 65-75.
40 M. K. Mulligan and J. P. Rothstein, Microfluid Nanofluid, 2012, 13, 65-73.

41 E. Amstad, M. Chemama, M. Eggersdorfer, L. R. Arriaga, M. P. Brenner and D. A. Weitz, Lab Chip, 2016, 16, 4163-4172.

42 W. Li, J. Greener, D. Voicu and E. Kumacheva, Lab Chip, 2009, 9, 2715-2721.

43 M. Muluneh and D. Issadore, Lab Chip, 2013, 13, 4750-4754.

44 D. M. Headen, J. R. García and A. J. García, Microsystems \& Nanoengineering, 2018, 4, 17076.

45 D. Bardin, M. R. Kendall, P. A. Dayton and A. P. Lee, Biomicrofluidics, 2013, 7, 034112.

46 G. Tetradis-Meris, D. Rossetti, C. Pulido de Torres, R. Cao, G. Lian and R. Janes, Ind. Eng. Chem. Res., 2009, 48, 8881-8889.

47 H.-H. Jeong, V. R. Yelleswarapu, S. Yadavali, D. Issadore and D. Lee, Lab on a Chip, 2015, 15, 43874392.

48 S.-H. Kim, J. W. Kim, D.-H. Kim, S.-H. Han and D. A. Weitz, Microfluid Nanofluid, 2013, 14, 509-514.

49 O. J. Miller, A. El Harrak, T. Mangeat, J.-C. Baret, L. Frenz, B. El Debs, E. Mayot, M. L. Samuels, E. K. Rooney, P. Dieu, M. Galvan, D. R. Link and A. D. Griffiths, Proc. Natl. Acad. Sci. U.S.A., 2012, 109, 378383.

50 J. Clausell-Tormos, A. D. Griffiths and C. A. Merten, Lab Chip, 2010, 10, 1302-1307.

51 T. S. Kaminski, S. Jakiela, M. A. Czekalska, W. Postek and P. Garstecki, Lab Chip, 2012, 12, 3995-4002.

52 U. Tangen, G. A. S. Minero, A. Sharma, P. F. Wagler, R. Cohen, O. Raz, T. Marx, T. Ben-Yehezkel and J. S. McCaskill, Biomicrofluidics, 2015, 9, 044103.

53 H. Zec, T. D. Rane and T.-H. Wang, Lab Chip, 2012, 12, 3055-3062.

54 G. Gines, R. Menezes, Nara, Kaori, Kirstetter, AnneSophie, Taly, Valérie and Rondelez, Yannick, bioarXiv, , DOI:https://doi.org/10.1101/701276.

55 J. Lim, O. Caen, J. Vrignon, M. Konrad, V. Taly and J.-C. Baret, Biomicrofluidics, 2015, 9, 034101.

56 L. B. Pinheiro, V. A. Coleman, C. M. Hindson, J. Herrmann, B. J. Hindson, S. Bhat and K. R. Emslie, Anal. Chem., 2012, 84, 1003-1011.

57 J. Madic, C. Jovelet, J. Lopez, B. André, J. Fatien, I. Miran, A. Honoré, L. Mezquita, B. Besse, L. Lacroix and M. Droniou, Oncotarget, 2018, 9, 37393-37406.

58 D. H. Wilson, D. M. Rissin, C. W. Kan, D. R. Fournier, T. Piech, T. G. Campbell, R. E. Meyer, M. W. Fishburn, C. Cabrera, P. P. Patel, E. Frew, Y. Chen, L. Chang, E. P. Ferrell, V. von Einem, W. McGuigan, M. Reinhardt, H. Sayer, C. Vielsack and D. C. Duffy, J Lab Autom., 2016, 21, 533-547.

59 K. Montagne, G. Gines, T. Fujii and Y. Rondelez, Nature Communications, 2016, 7, 13474.

60 Y. Zhang and H.-R. Jiang, Analytica Chimica Acta, 2016, 914, 7-16.

61 P. J. Obeid, T. K. Christopoulos, H. J. Crabtree and C. J. Backhouse, Anal. Chem., 2003, 75, 288-295. 
62 N. Park, S. Kim and J. H. Hahn, Anal. Chem., 2003, 75, 6029-6033.

63 K. D. Dorfman, M. Chabert, J.-H. Codarbox, G. Rousseau, P. de Cremoux and J.-L. Viovy, Anal. Chem., 2005, 77, 3700-3704.

64 M. Curcio and J. Roeraade, Anal. Chem., 2003, 75, 17.

65 I. Hudecova, Clinical Biochemistry, 2015, 48, 948-956.

66 B. Vogelstein and K. W. Kinzler, PNAS, 1999, 96, 9236-9241.
67 S. Kaneda, K. Ono, T. Fukuba, T. Nojima, T. Yamamoto and T. Fujii, Anal Sci, 2012, 28, 39-44.

68 A. S. Basu, SLAS TECHNOLOGY: Translating Life Sciences Innovation, 2017, 22, 369-386.

69 A. Baccouche, K. Montagne, A. Padirac, T. Fujii and Y. Rondelez, Methods, 2014, 67, 234-249.

70 A. Yamagata, R. Masui, Y. Kakuta, S. Kuramitsu and K. Fukuyama, Nucleic Acids Res, 2001, 29, 4617-4624. 


\section{Supplementary Material for}

\section{Streamlined digital bioassays with a 3D printed sample changer}

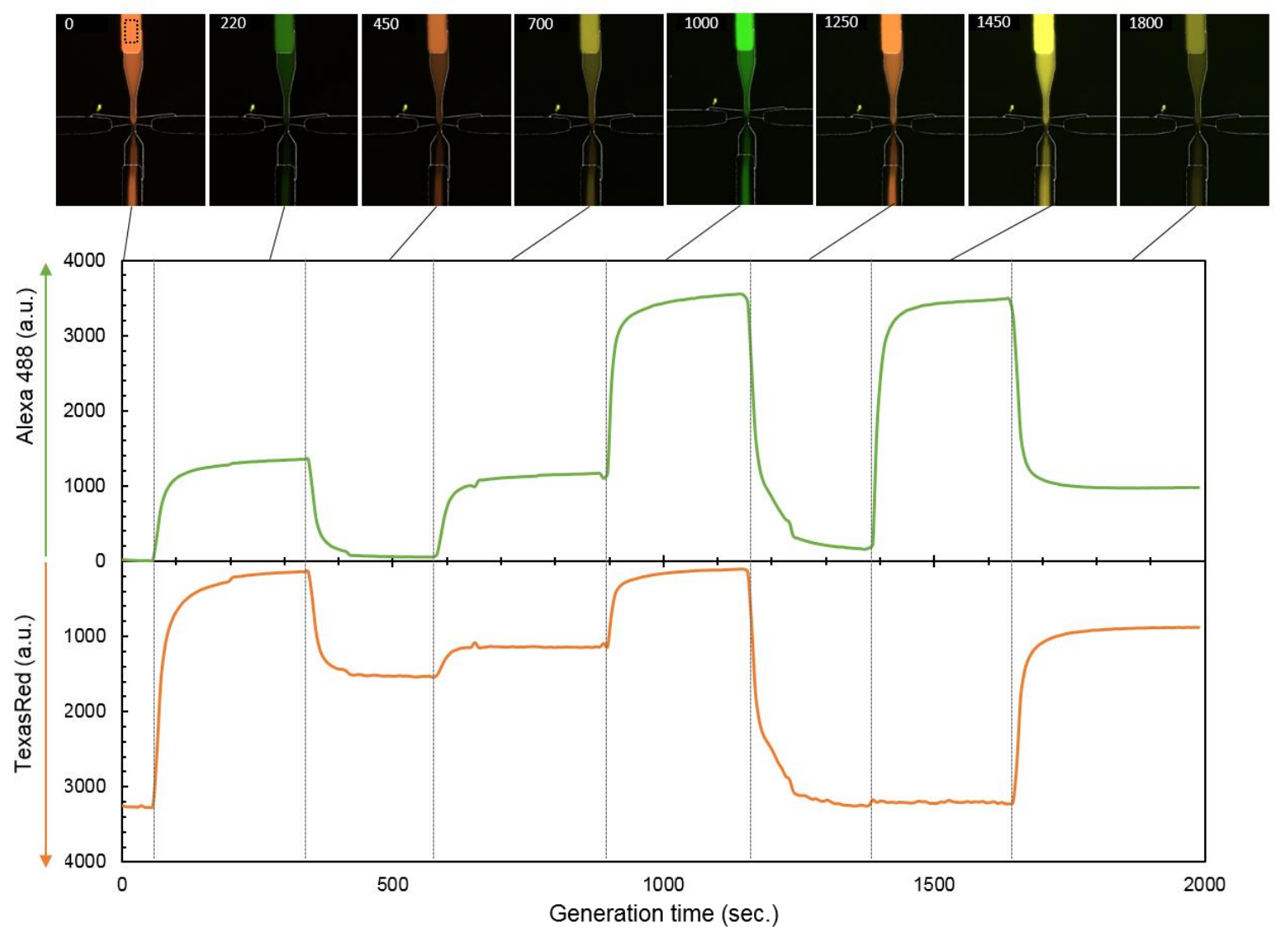

Figure S 1. Time lapse of the droplet generation of $\mathbf{8}$ barcoded using a flow focusing device. From sample 1 to 8 the Alexa488/Texas barcode concentrations in $\mathrm{nM}$ are $0 / 400,200 / 0,0 / 200,200 / 200,400 / 0,0 / 400,400 / 400$ and 200/200. The microscopy snapshot correspond a composite image of the chip nozzle (bright field, Texas red and Alexa488 fluorescence channels). The average fluorescence over a portion of the inlet channel (black rectangle in the top left image) is plotted as a function of the generation time. 

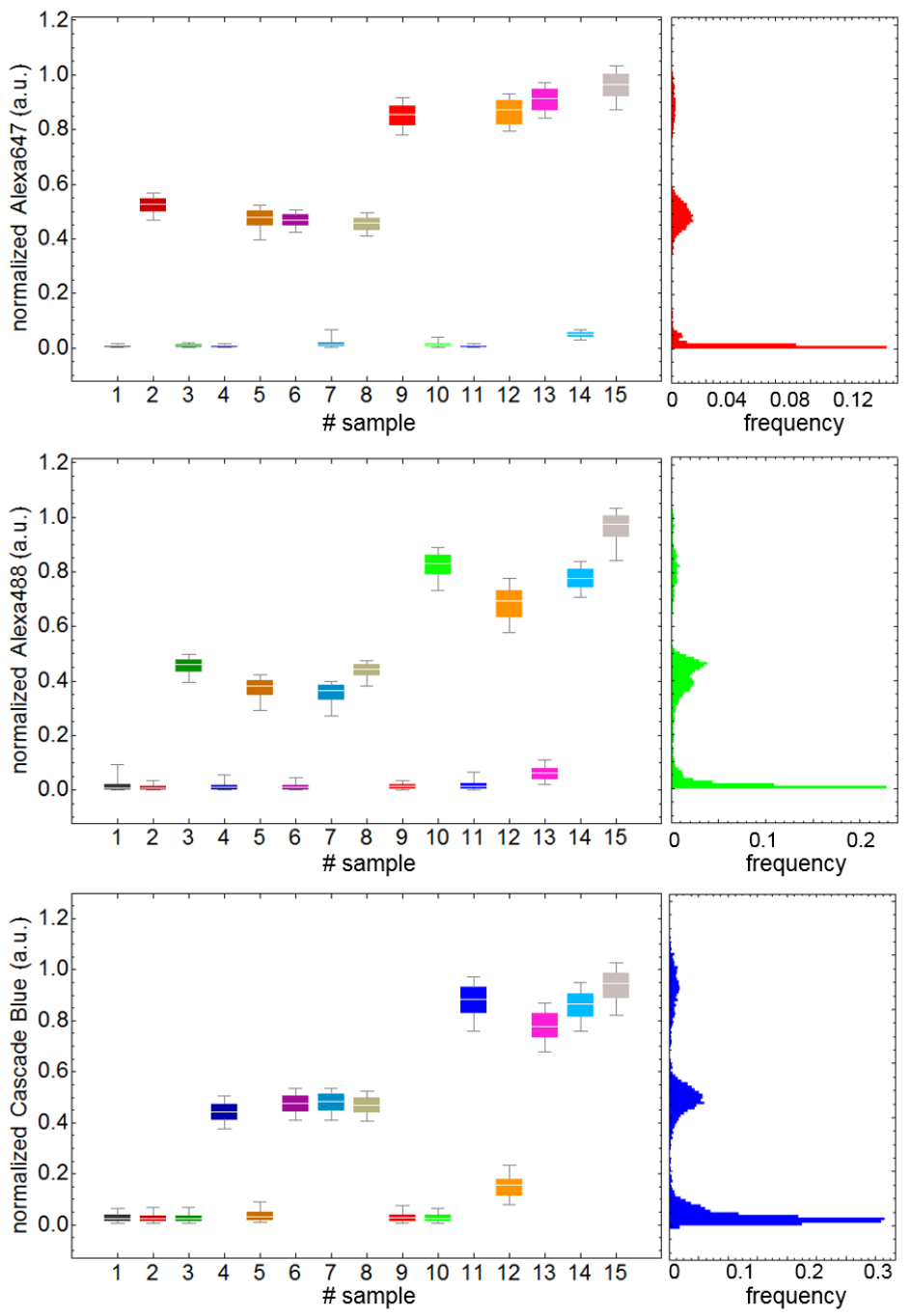

Figure S 2. Extended data from Figure 2. Here, we analyse the fluorescence distribution for the 15 droplet populations in the 3 fluorescence channel (Alexa647, Alexa488 and Cascade Blue). Boxes and whiskers represent the 25-75\% and 10$90 \%$ distribution of the droplet fluorescence for each sample. Histograms on the left show the distribution over the full droplet population. 

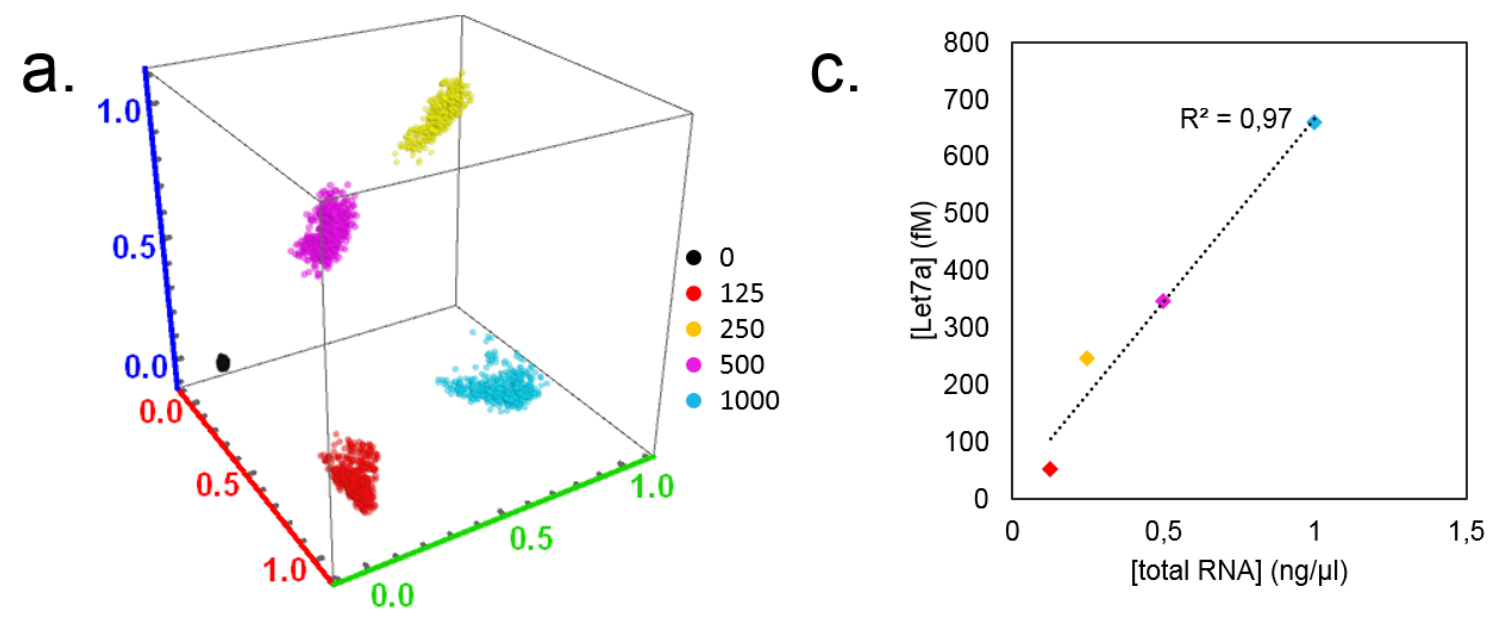

D.
\begin{tabular}{|r|r|r|r|r|r|r|}
\hline $\begin{array}{c}\text { microRNA } \\
\text { target }\end{array}$ & \# droplets & $\begin{array}{c}\text { \# droplets } \\
\text { pos }\end{array}$ & $\begin{array}{c}\% \text { droplet } \\
\text { pos }\end{array}$ & $\begin{array}{c}\text { droplet } \\
\text { volume (fL) }\end{array}$ & \multicolumn{1}{c|}{$\lambda$} & $\begin{array}{r}\text { Measured } \\
\text { conc.(pM) }\end{array}$ \\
\hline \hline $0,0 \mathrm{E}+00$ & 15190 & 251 & $1,7 \%$ & 520 & $1,7 \mathrm{E}-02+/-2,2 \mathrm{E}-03$ & 52,77 \\
$1,3 \mathrm{E}-01$ & 22629 & 744 & $3,3 \%$ & 520 & $3,3 \mathrm{E}-02+/-2,2 \mathrm{E}-03$ & 53,11 \\
$2,5 \mathrm{E}-01$ & 8390 & 754 & $9,0 \%$ & 520 & $9,4 \mathrm{E}-02+/-3,8 \mathrm{E}-03$ & 245,48 \\
$5,0 \mathrm{E}-01$ & 8622 & 1020 & $11,8 \%$ & 520 & $1,3 \mathrm{E}-01+/-2,9 \mathrm{E}-03$ & 346,00 \\
$1,0 \mathrm{E}+00$ & 29405 & 5918 & $20,1 \%$ & 520 & $2,2 \mathrm{E}-01+/-1,0 \mathrm{E}-02$ & 658,97 \\
\hline
\end{tabular}

Figure S 3. Detection of Let7a in total RNA extract from human colon tissue. Five barcoded amplification mix containing a varying concentration of total RNA extract are emulsified and Let7a is quantified by a digital readout. a. 3D plot of the barcode fluorescence for each droplet population. b. Extracted data from the droplet analysis after isothermal incubation. $\mathbf{c}$. The measured Let7a concentration (LOB substrated) is plotted against the total RNA extract concentration. The linear correlation demonstrates the proper quantification of the microRNA target in this biological sample.

a.

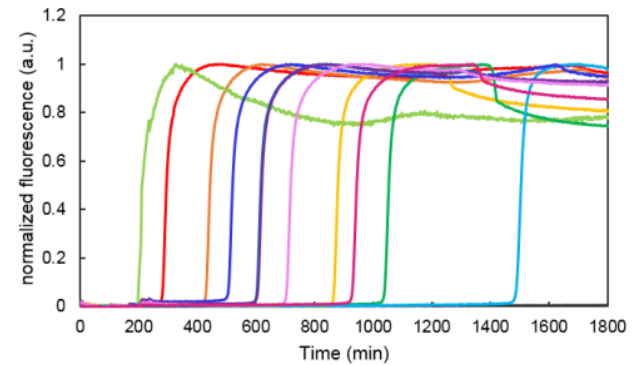

b.

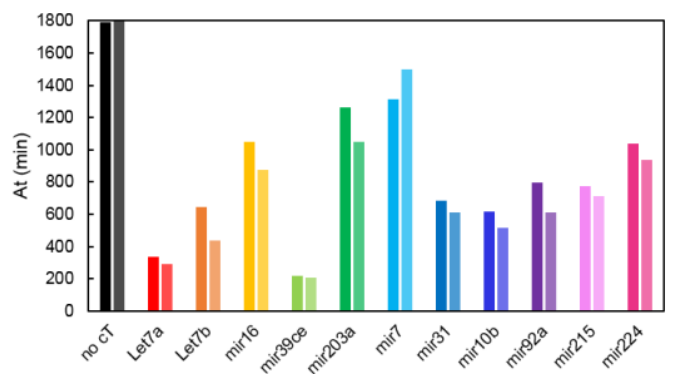

C.

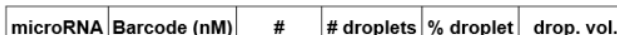

\# droplets $\%$ droplet $\quad$ drop. vol.

\begin{tabular}{|l|c|c|c|r|}
\hline \multicolumn{1}{|c|}{$\begin{array}{l}\text { microet } \\
\text { target }\end{array}$} & \multicolumn{2}{|c|}{ C } & \multicolumn{1}{c|}{ T } & droplets \\
\hline no cT & 0 & 0 & 0 & 54 \\
Let7a & 300 & 0 & 0 & 53 \\
Let7b & 0 & 300 & 0 & 71 \\
mir16 & 0 & 0 & 300 & 73 \\
mir39ce & 150 & 150 & 0 & 95 \\
mir203a & 0 & 150 & 150 & 91 \\
mir7 & 150 & 0 & 150 & 137 \\
mir31* & 300 & 300 & 0 & 102 \\
mir10b & 300 & 0 & 300 & 98 \\
mir92a & 0 & 300 & 300 & 55 \\
mir215 & 300 & 300 & 300 & 117 \\
mir224 & 150 & 150 & 150 & 134 \\
\hline
\end{tabular}

\begin{tabular}{|r|r|}
$\begin{array}{c}\text { \# } \\
\text { olets }\end{array}$ & $\begin{array}{c}\text { \# droplets } \\
\text { pos }\end{array}$ \\
5409 & \\
5325 & 1136 \\
7163 & 678 \\
7385 & 525 \\
9580 & 3289 \\
9157 & 803 \\
13732 & 752 \\
10250 & 531 \\
9886 & 692 \\
5585 & 414 \\
11706 & 617 \\
13418 & 482 \\
\hline
\end{tabular}

\begin{tabular}{r|r|r} 
pos & $\begin{array}{r}\text { p droplet } \\
\text { pos }\end{array}$ & $\begin{array}{c}\text { drop. vol. } \\
\text { (fL) }\end{array}$ \\
\hline 0 & $0.0 \%$ & \\
1136 & $21.3 \%$ & \\
678 & $9.5 \%$ & \\
525 & $7.1 \%$ & \\
3289 & $34.3 \%$ & \\
803 & $8.8 \%$ & \\
752 & $5.5 \%$ & \\
531 & $5.2 \%$ & \\
692 & $7.0 \%$ & \\
414 & $7.4 \%$ & \\
617 & $5.3 \%$ & \\
482 & $3.6 \%$ & \\
\hline
\end{tabular}

\begin{tabular}{|c|c|c|c|}
\hline vol. & & $\lambda$ & $\begin{array}{l}\text { Measured } \\
\text { conc. }(\mathrm{pM})\end{array}$ \\
\hline 700 & $0.0 \mathrm{E}+00$ & $+/-8.0 \mathrm{E}-04$ & 0.00 \\
\hline 700 & $2.4 \mathrm{E}-01$ & $+/-1.2 \mathrm{E}-03$ & 0.57 \\
\hline 700 & $9.9 \mathrm{E}-02$ & $+1-3.2 \mathrm{E}-03$ & 0.24 \\
\hline 700 & 7.4E-02 & $+/-4.9 \mathrm{E}-03$ & 0.17 \\
\hline 700 & 4.2E-01 & $+/-2.0 \mathrm{E}-02$ & 1.00 \\
\hline 700 & $9.2 \mathrm{E}-02$ & $+/-1.8 \mathrm{E}-01$ & 0.22 \\
\hline 700 & $5.6 \mathrm{E}-02$ & $+/-8.2 \mathrm{E}-04$ & 0.13 \\
\hline 700 & $5.3 \mathrm{E}-02$ & $+/-1.5 \mathrm{E}-03$ & 0.13 \\
\hline 700 & $7.3 \mathrm{E}-02$ & $+/-2.6 \mathrm{E}-03$ & 0.17 \\
\hline 700 & 7.7E-02 & $+/-5.2 \mathrm{E}-03$ & 0.18 \\
\hline 700 & $5.4 \mathrm{E}-02$ & $+/-4.1 \mathrm{E}-02$ & 0.13 \\
\hline 700 & $3.7 \mathrm{E}-02$ & $+/-3.7 \mathrm{E}-01$ & 0.09 \\
\hline
\end{tabular}

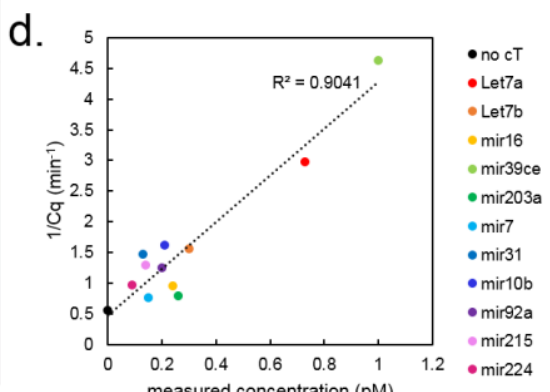

Figure S 4. Extended data from Figure 4. a. Real-time monitoring of the amplification reaction in solution (prior to emulsification). b. Extracted amplification time $\left(A_{t}\right.$, corresponding to the time when the fluorescence curves reaches 10 $\%$ of the maximum fluorescence). c. Extracted data from the droplets analysis after incubation of the emulsion (cf. Supplementary Figure 6 for the analysis procedure). "C", "A" and "T" denote Cascade Blue, Alexa488 and TexasRedconjugated dextrans, repectively. $\mathbf{d}$. The invert of the $A_{t}$ is plotted as a function of the measured concentration by droplet digital readout. We observe a linear correlation $\left(\mathrm{R}^{2}=0.90\right)$ that supports the reliability of the digital measurement. Note 
that a perfect linear correlation is not expected, as the results from the realtime experiment are not standardized (this would require a calibration curve for each microRNA).

a.
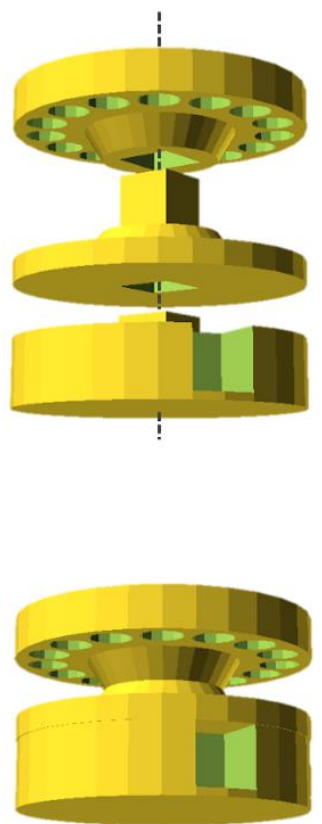

b.
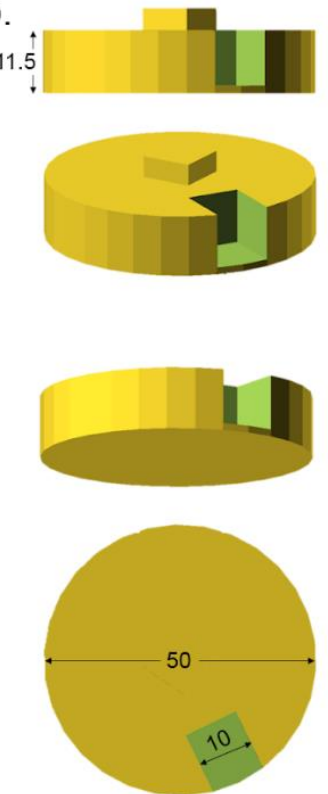

C.
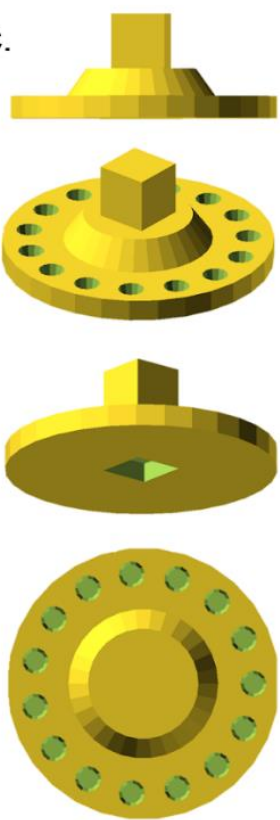

d.
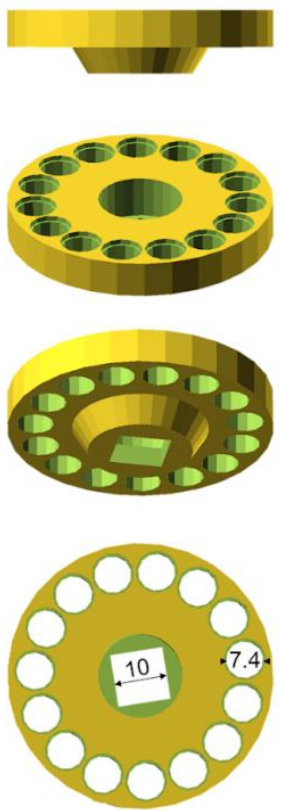

Figure S 5. OpenSCAD design of the 3D printed sample tray. a. The sample tray consists in the assembly of 3 parts. b. Magnet holder (bottom part). b. Middle part. c. Top part. The device was printed using PLA printing filament $(30 \mathrm{~g}=$ $\sim 2 €)$ 
a.

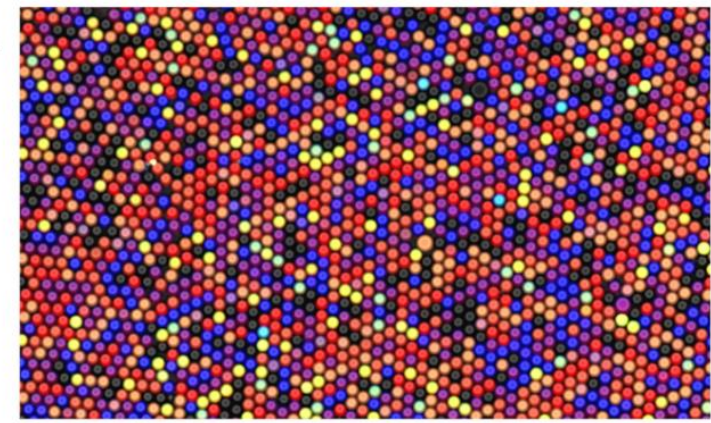

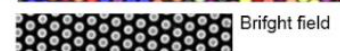

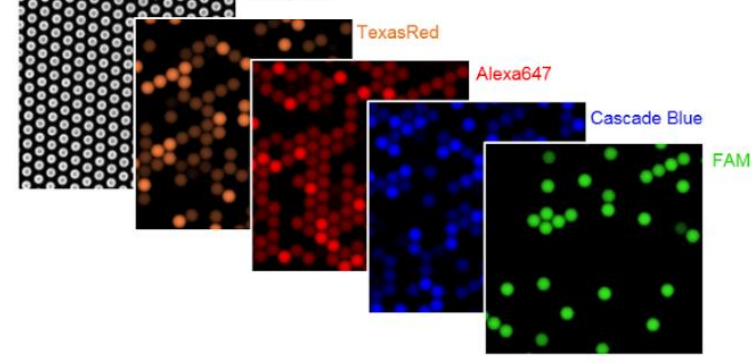

b.

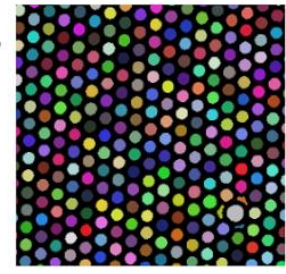

d.

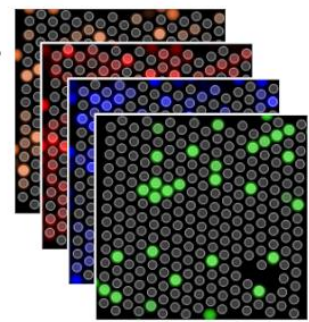

e.
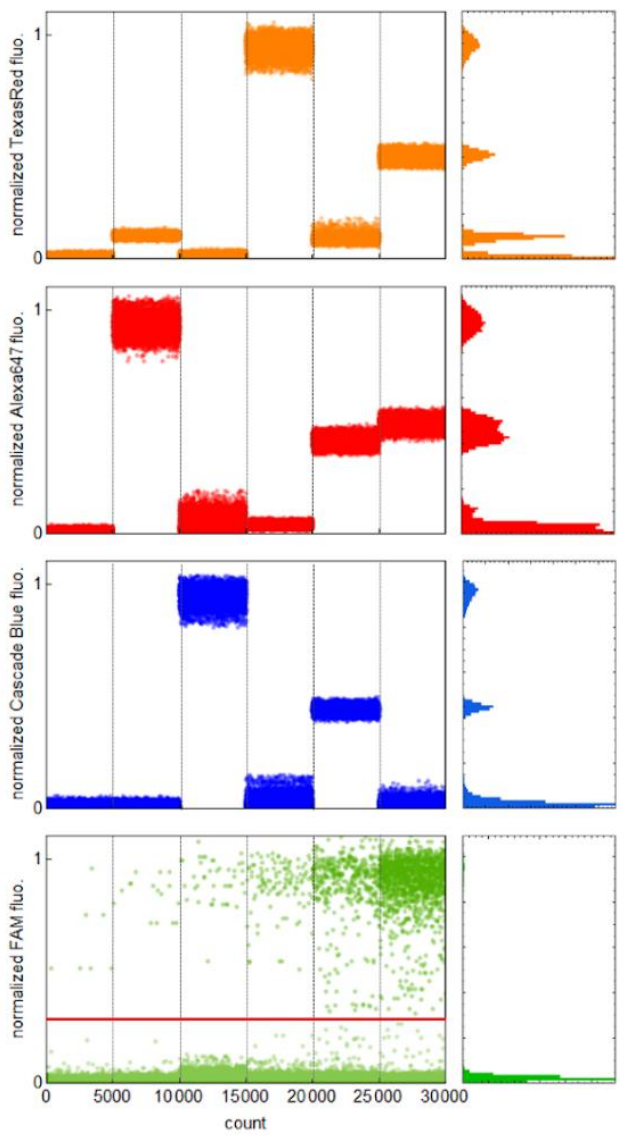

f.

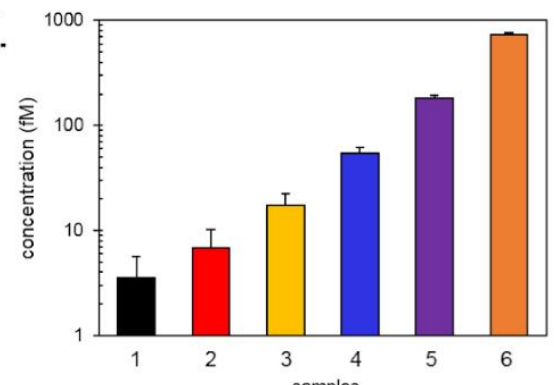

Figure S 6. Droplet analysis. The experiment we depict here corresponds to the quantification of the synthetic microRNA Let7a by digital isothermal amplification. From sample 1 to 6 , the expected concentration of Let7a is $0,2.7$, $11,44,175$ and $700 \mathrm{fM}$ respectively. a. A monolayer of droplets is imaged by transmission microscopy (bright field) and epifluorescence microscopy (including here the 3 channels for the barcodes TexasRed, Alexa647 and Cascade Blue and the channel corresponding to the fluorescent output of the digital readout, FAM). $\mathbf{b}$. The bright field image is used to segment individual droplets. c. The droplets are selected on the basis of their size (radius in pixel) and circularity $(>0.9)$. The blue box includes all droplets that fit the size and circularity parameters. An additional density filter, excluding the few droplets that are isolated in this box, is applied and the object represented in red are kept for the downstream analysis. d. 3D plot of the droplets fluorescence barcodes : for each selected droplet, the fluorescence in each channel is averaged over a disk of center corresponding to the object centroid and radius $\mathrm{r}$ ( $\mathrm{r}$ being slightly smaller than the droplet radius). The droplets population are sorted according to their fluorescence in the barcode's channels. e. Fluorescence plots of the barcodes and probe fluorescence after sorting. f. The concentration of the target molecule (here, Let7a) is calculated using the Poisson law, assuming a random distribution of the targets across the droplets 

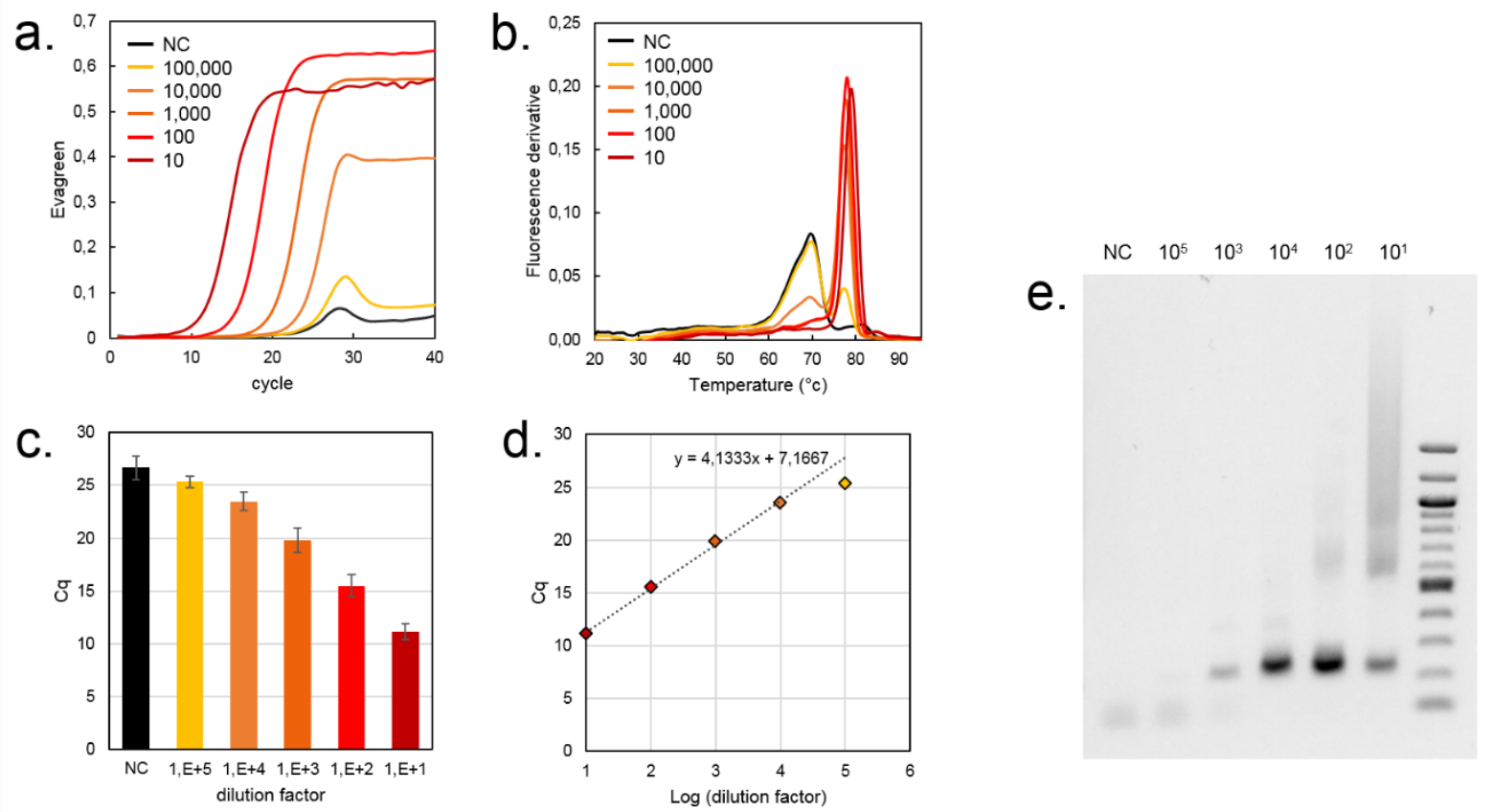

Figure S 7. Real-time PCR of the 163 bases long amplicon starting with various template dilutions ranging from a $10^{1}$ to a $10^{5}$-dilution factor. a. Real-time monitoring of the qPCR amplification in solution by Evagreen fluorescence signal recording. b. Corresponding melt curves. c. Extracted cycle quantification (Cq) values from the real-time curve analysis. d. Cq values are plotted as a function of the used dilution factor. We observe a linear correlation $\left(\mathrm{R}^{2}=0.99\right)$ similar to the one observed in Figure 6 with ddPCR. e. Amplicon migration in an $0.8 \% \mathrm{w} / \mathrm{v}$ agarose gel.

a.

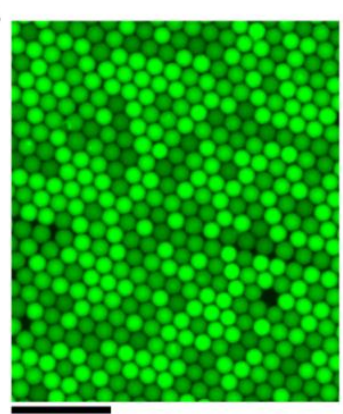

$50 \mu \mathrm{m}$
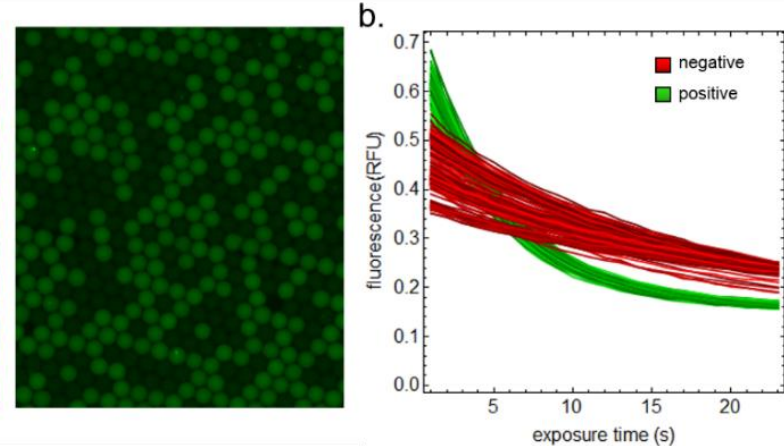

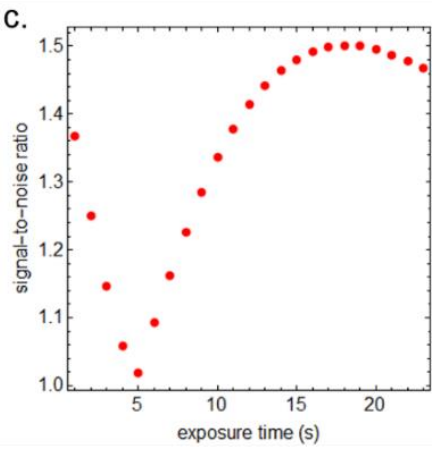

Figure S 8. Inverted contrast following photobleaching of droplets after digital PCR. a. Microscopy images of a $2 \mathrm{D}$ droplet array at after an exposure time of $\mathrm{t}=1 \mathrm{~s}$ (left) and $\mathrm{t}=20 \mathrm{~s}$ (right). The acquisition time is $1 \mathrm{~s}$. After PCR amplification, we noticed that Evagreen fluorescence is more resistant to photobleaching in negative droplets than in positive droplets. As a result, the positive droplets become less fluorescent than the negative droplet, contrary to classical droplet digital PCR readout. b. Fluorescence emission of the doplets as a function of the exposure time (red time traces $=$ negative droplets, green time traces $=$ positive droplets). $\mathbf{c}$. Signal-to-noise ratio $(\mathrm{SNR})$ as a function of the exposure time $(\mathrm{SNR}=1.37$ at $\mathrm{t}=1 \mathrm{~s}$ and 1.47 at $\mathrm{t}=20 \mathrm{~s})$. 
Table S 1. Nucleic acid sequences used throughout the study. ."*" denotes phosphorothioate backbone modification. " $p$ " denotes 3'-phosphate modification. Upper and lower cases represent 2'-deoxyribonucleotide and ribonucleotide, respectively. BHQ2 stands for Black Hole Quencher 2 and is used as a quencher of the Atto633 fluorophore.

\begin{tabular}{|c|c|c|}
\hline ID & Sequence & function \\
\hline \multicolumn{3}{|c|}{ Isothermal amplification for the digital detection of microRNA } \\
\hline$\alpha$ & CATTCTGGACTG & \\
\hline atoa & $C^{*} A^{*} G^{*} T^{*}$ CCAGAATGCAGTCCAGAAp & aT \\
\hline pTa & $T^{*} T^{\star} T^{*} T^{*} T C A G T C C A G A A T G p$ & pT \\
\hline $\mathrm{rTa}$ & Atto633 ${ }^{*} A^{*} T^{*}$ TCTGAATGCAGTCCAGAAT BHQ2 & rT \\
\hline Let7atoa & TGCAGTCCAGAAGTTTGACTCAAACTATACAACCTACTACCTCAp & cT \\
\hline Let7btoa & TG-CAGTCCAGAA-GTTTGACT-CAAACCACACAACCTACTACCTCA & cT \\
\hline 16 toa & $\begin{array}{l}\text { TG-CAGTCCAGAA-GTTTGACTC-A- } \\
\text { CGCCAAUAUUUACGTGCUGCUA }\end{array}$ & cT \\
\hline 39toa & TG-CAGTCCAGAA-GTTTGACTC-A-CAAGCTGATTTACACCC & cT \\
\hline 203atoa & $\begin{array}{l}\text { TG-CAGTCCAGAA-GTTTGGACTCAA- } \\
\text { CTAGTGGTCCTAAACATTTCAC }\end{array}$ & cT \\
\hline 7toa & $\begin{array}{l}\text { TGCAGTCCAGAA-GTTTGACTCA- } \\
\text { AACAACAAAATCACTAGTCTTCCA }\end{array}$ & cT \\
\hline 31 toa & TG-CAGTCCAGAA-GTTTGACTC-A-GATGGCAATATGTTGGCA & cT \\
\hline 10btoa & $\begin{array}{l}\text { TGCAGTCCAGAA-GTTTGACTCA- } \\
\text { CACAAATTCGGTTCTACAGGGTA }\end{array}$ & cT \\
\hline 92atod & TG-CAGTCCAGAA-GTTTGACTCAAGCATTGCAACCGATCCCAACC & сT \\
\hline 215 toa & TG-CAGTCCAGAA-GTTTGACTCA-GTCTGTCAATTCATAGGTCAT & cT \\
\hline 124toa & TG-CAGTCCAGAA-GTTTGACTCA-GGCATTCACCGCGTGCCTT & cT \\
\hline Let7a-5p & ugagguaguagguuguauaguu & microRNA \\
\hline Let7b-5p & ugagguaguagguugugugguu & microRNA \\
\hline miR-16-5p & uagcagcacguaaauauuggcg & microRNA \\
\hline cel-miR39-5p & ucaccggguguaaaucagcuug & microRNA \\
\hline miR-203a-3p & gugaaauguuuaggaccacuag & microRNA \\
\hline$m i R-7-5 p$ & uggaagacuagugauuuuguuguu & microRNA \\
\hline miR-31- & ugcuaugccaacauauugccauc & microRNA \\
\hline$m i R-10 b-5 p$ & uacccuguagaaccgaauuugug & microRNA \\
\hline miR-92a-5p & agguugggaucgguugcaaugcu & microRNA \\
\hline miR215-5p & augaccuaugaauugacagac & microRNA \\
\hline miR124-3p & aaggcacgcggugaaugcc & microRNA \\
\hline \multicolumn{3}{|c|}{ Droplet digital PCR } \\
\hline fw primer & CCATGCTAAGGAATTACAG & $\begin{array}{l}\text { forward } \\
\text { primer }\end{array}$ \\
\hline rv primer & ATTTTTATTTGCAATGAAGCG & $\begin{array}{l}\text { reverse } \\
\text { primer }\end{array}$ \\
\hline
\end{tabular}

